\title{
Merging data from genetic and epigenetic approaches to better understand autistic spectrum disorder
}

\begin{abstract}
Autism spectrum disorder (ASD) is a complex neurodevelopmental disorder that is characterized by a wide range of cognitive and behavioral abnormalities. Genetic research has identified large numbers of genes that contribute to ASD phenotypes. There is compelling evidence that environmental factors contribute to ASD through influences that differentially impact the brain through epigenetic mechanisms. Both genetic mutations and epigenetic influences alter gene expression in different cell types of the brain. Mutations impact the expression of large numbers of genes and also have downstream consequences depending on specific pathways associated with the mutation. Environmental factors impact the expression of sets of genes by altering methylation/hydroxymethylation patterns, local histone modification patterns and chromatin remodeling. Herein, we discuss recent developments in the research of ASD with a focus on epigenetic pathways as a complement to current genetic screening.
\end{abstract}

Keywords: common final pathway $\bullet$ DNA hydroxymethylation $\bullet$ DNA methylation $\bullet$ genetics - prenatal environment $\bullet$ transcriptome

The Center for Disease Control estimates that approximately one in 88 children are diagnosed with autism spectrum disorder (ASD). ASD is a neurodevelopmental disorder characterized by symptoms that include impaired social and contextual interactions, difficulties with communication skills and restrictive or repetitive patterns of behavior. ASD is considered to be genetically complex and inherited ASD can be caused by either single-gene defects or chromosomal abnormalities. It is also thought that multiple alleles of small effect that are present in high frequency in the population contribute to ASD heritability. ASD is symptomatically heterogeneous with many of the diagnostic symptoms showing considerable variability in severity. Females with ASD exhibit greater deficits in social communication, lower cognitive ability, reduced levels of restricted interests, weaker adaptive skills, as well as, greater difficulties with externalizing problems when compared with males [1]. Children with ASD exhibit a broad range of sensory differences both in terms of severity and with respect to sensory subtype focus [2].

The broad symptomatic profile of patients with ASD has hampered the search for diagnostic biomarkers of the disorder. Idiopathic (nonsyndromic) ASD, for which an underlying cause has not been identified, represent the majority of cases. Individuals with ASD traced to either single-gene mutations or defined chromosomal/cytogenetic abnormalities (syndromic autism) exhibit characteristic features that are often accompanied by additional comorbidities [3,4]. Genetically defined syndromic disorders which phenotypically overlap with ASD include Rett, Fragile X, Tuberous sclerosis, Asperger's, Smith-Lemli-Opitz syndromes, 22q11.2del, etc. [5]. Adding to these complexities is the observation that $70 \%$ of children diagnosed with idiopathic ASD exhibit comorbid medical, developmental or psychiatric conditions $[3,6]$, including intellectual disability [7]. According to one review, over 100 genes have been linked to syndromic forms of autism [8]. In addition, there
Dennis R Grayson ${ }^{1}$

\& Alessandro Guidotti ${ }^{*, 1}$

'Department of Psychiatry, The

Psychiatric Institute, University of Illinois

at Chicago, 1601 W. Taylor St., Chicago, IL 60607, USA

*Author for correspondence:

Tel.: +1 3124134577

dgrayson@psych.uic.edu
Future fsg 
are over 400 high-confidence, nonsyndromic autism related genes that have been implicated by genetic approaches [9]. Interestingly, not all children with a predisposing genotype develop ASD [10]. This suggests that additional environmental factors likely interact with the genome in producing ASD. We discuss current findings related to molecular mechanisms of ASD and propose that the fetal environment interacts with predisposing genotypes to alter the developmental trajectory of cellular transcription in the brain.

Individuals diagnosed with ASD are often associated with alterations in the expression of specific genes depending on the presence of specific polymorphisms in the genotype. For example, null alleles in MET produce a frameshift and premature stop codon which results in little if any protein arising from the affected allele [11]. The MET proto-oncogene is a candidate ASD susceptibility gene. In addition to the genotype, the prenatal environment induces factors that modify the expression of distinct and likely overlapping gene sets. It seems plausible that the transcriptome of affected individuals reflects contributions from both the genetic background (genotype) and from environmentally mediated changes to the developmental transcription program. In other words, even though ASD is considered a complex genetic disorder, the complexity lies not only in the genetics, but rather in how the environment interacts at the level of the genotype to influence gene expression relative to neurotypical development. Ultimately, gene-environment interactions determine the specific ASD phenotypes associated with each patient. Increased risk of ASD is associated with mutations in genes that overlap with chromatin remodeling proteins, transcriptional regulators and synapse-associated proteins [12]. Interestingly, these genes are also targets of environmentally induced changes in gene expression.

\section{ASD genetics: background}

During the last decade, it has become increasingly clear that in addition to SNPs, copy number variants (CNVs) account for a significant percentage of ASD disease burden. During the last decade, both de novo and inherited gene mutations have been shown to contribute to increased risk of psychiatric disorders, including ASD. Whole exome sequencing studies have led to the identification of de novo CNVs in sporadic ASD patients, although specific variants are often rare and overlap with other psychiatric disorders [12,13]. The use of larger patient and control sample sizes has increased the confidence in the risk associated with specific CNVs. A recent analysis of extended ASD pedigrees suggests that the etiology of ASD is complex and does not necessarily involve the same genetic mecha- nisms across even closely related cases [14]. Recent estimates suggest that the numbers of genes genetically associated with ASD are greater than 1000 [12]. At the same time, these loci account for only a small fraction of the estimated heritability. While it seems clear that advances in our understanding of the genetic causes of ASD have been made by recent findings, additional work is now needed to further our understanding of the underlying biology of how various risk genes interact and the role of the environment in shaping these interactions.

In spite of the recent identification of large numbers of ASD risk genes and associated pathways, current estimates indicate that syndromic ASD accounts for less than $10 \%$ of total diagnoses [15]. Current estimates of heritability vary between 38 and $90 \%$. A recent study of Swedish children was used to determine the relative recurrent risk of ASD [16]. Results show that the individual risk of ASD increased with genetic relatedness. Moreover, the heritability of ASD was estimated at $50 \%$ indicating that half of the risk is likely due to environmental factors that may either be shared or not shared [16].

Many of the mutations that have been implicated in ASD by genetic studies reside in genes that encode proteins associated with synaptic function, transcriptional regulation and chromatin-remodeling [12]. The functional diversity of genes implicated in ASD suggests the possibility that the etiology of ASD may be as heterogeneous as is the variable symptomatology [8]. There is also considerable overlap in genes associated with ASD and intellectual disability, as well as between ASD and epilepsy [8]. This suggests that the genetic origins of ASD may not only be difficult to tease apart but that the etiological heterogeneity of ASD may be just as complex. However, reducing phenotypic hetergeneity (by subphenotyping) did not increase the statistical power of a recent association analysis, suggesting the possibility that phenotypic heterogeneity is not simply the consequence of genetic variation [17]. Collectively, the large numbers of syndromic ASD-like disorders and the associated genetic variability indicate that ASD may represent a common end point for a collection of neurodevelopmental disorders that arise from a finite set of genes associated with brain function. While we are a long way from appreciating how genetic background influences global gene expression profiles, it seems plausible that the ultimate impact of genetic mutation lies in the downstream consequences of altered gene expression and function. The goal for the foreseeable future is to provide a better understanding of how specific genes function to disrupt specific biological pathways and whether these pathways are amenable to pharmacotherapeutic interventions. 


\section{Transcriptome profiles in ASD brain}

As noted above, the symptomatic profile of individual patients is heterogenous. This observation when coupled with the concept that the etiological heterogeneity of ASD is complex leads to the suggestion that biochemical studies of ASD brain may not prove informative. Instead, however, what is emerging from ongoing mechanistic studies across the world is that the pathophysiology of ASD may converge on common biological pathways [18-20]. It seems likely that the observed symptom heterogeneity that is typical of ASD clinical presentation arises as a result of common pathophysiological mechanisms that interfere at different times (different trimesters) or with distinct brain structures (different cortical areas, hippocampus, etc.) during development. In addition, it also seems plausible that the variable ASD symptomatology associated with idiopathic ASD arises due to the consequences of epigenetic mechanisms acting on multiple, distinct genetic locations at different times and brain regions during development.

Many of the genes enriched in lists of genetic variants associated with increased ASD risk are linked to neuronal function. Analysis of gene expression relationships in specific human brain regions allows for the identification of modules of interconnected genes that correspond to distinct cell types. The modules, constructed by Weighted Gene Co-Expression Network Analysis (WGCNA) of genome-wide transcriptome data [21], are designed to provide information regarding coexpression networks that correspond to neurons, oligodendrocytes, astrocytes and microglia [22,23]. Moreover, they provide information regarding specific functionalities associated with the transcriptional programs of coexpressed genes. These relationships are useful in defining genes that are differentially expressed across multiple neuropsychiatric diseases [24]. Transcriptome studies of postmortem ASD brain show that modules of genes associated with brain function are dysregulated in ASD cortex. Comparisons of coexpressed genes in different brain structures show that regional variations in gene expression that highlight differences between frontal and temporal cortex are attenuated in ASD brain [25]. This finding supports the idea that gene expression related to cortical patterning is likely disrupted. WGCNA of the genes downregulated in ASD brain regions illustrate that one of the modules consists of genes related to both interneuron and synaptic function. Many of the synaptic function mRNAs have also been identified as ASD-susceptibility or risk genes. In addition to the decreased expression of genes associated with neuronal and synaptic function, the expression of genes enriched in astrocytes and microglia are increased in ASD cortex [25]. The involvement of genes associated with synaptic function and immune responses suggests the possibility that neuroinflammation or altered immune function in the brain may be responsible for the disrupted neuronal/synaptic function observed in ASD [26].

A recent transcriptome analysis of multiple ASD brain regions confirms these findings and also implicates genes associated with the activation of microglia and the immune response [20]. The microglial cell state module, which negatively correlates with the synaptic transmission module, includes genes associated with the type I IFN pathway, viral response genes and cytokine-mediated signaling pathway genes. Microglia have been shown to be important to the process of synaptic pruning by engulfing material in the brain through the complement receptor pathway $[27,28]$. Synaptic pruning prevents the overaccumulation of neuronal connections that accumulate during neurodevelopment and is linked to specific genetic mutations common in ASD patients [29]. The observed microglial/immune system dysfunction also raises the possibility that transcription profiles of ASD brain mirror the consequences of environmental insults such as prenatal infection.

\section{DNA methylation writers}

The downstream consequences of environmental factors such as maternal stress or infection reside in how cells of the brain respond to these prenatal or early life events. Transcriptionally active chromatin is open and characterized by the presence of transcription factors and coactivators that bind DNA in nucleosome-free regions. In closed chromatin, the DNA is condensed and bound by large numbers of repressor proteins. The transitions between open and closed chromatin states are facilitated, in part, by changes in the methylation status of the DNA. DNA methylation is a cell-type specific epigenetic modification that impacts chromatin architecture by influencing nucleosome positioning and the binding of various methylation readers to discrete regions of the genome. DNA methylation is critical during development of the brain and plays a key role in diverse processes from synaptic plasticity [30], learning and memory [31], to cognitive decline [32]. DNA methylation consists of the enzymatic addition of a methyl group to the $\mathrm{C} 5$ position of cytosine using $S$-adenosyl methionine and DNA as substrates. DNA methylation is a stable epigenetic mark that when located proximal to regulatory elements associated with transcription start sites, including promoters, most often facilitates the formation of a repressed chromatin state (reviewed in $[33,34]$ ). Approximately $70 \%$ of CpGs genome-wide are symmetrically methylated [35]. Regions of high CpG density, called CpG islands, are generally undermethylated as compared with other 
regions of the genome with moderate-to-low $\mathrm{CpG}$ density. Stretches of DNA flanking the CpG islands, called $\mathrm{CpG}$ island shores, are thought to contain sites corresponding to cell-type specific differential methylation [36]. Genome-wide mapping of DNA methylation in the frontal cortex of humans has shown that in addition to traditional $\mathrm{CpG}$ methylation, non-CpG methylation is prominent in brain [37-39]. Interestingly, the positions of $\mathrm{CpH}$ are remarkably well preserved between neurons of different individuals [40]. Non$\mathrm{CpG}$ methylation (or $\mathrm{CpH}$ methylation) is enriched at regions of low $\mathrm{CpG}$ density, in the vicinity of protein-DNA binding sites and, like $\mathrm{CpG}$ methylation, inversely correlates with gene expression [38,40]. Moreover, methylation of $\mathrm{CpH}$ occurs de novo during neuronal maturation and represents the majority of cell-type specific DNA methylation that promotes repressive chromatin and inhibits transcription [39]. In addition, determination of genome-wide methylation shows that megabase-sized regions of DNA exist that are devoid of $\mathrm{mCpH}$, and these so-called $\mathrm{mCpH}$ deserts occur in genes such as the immunoglobulin $\mathrm{VH}$ locus which encodes variable domains of the immunoglobulin heavy chain and in olfactory receptor gene clusters [40]. Comparisons of $\mathrm{mCpH} / \mathrm{CpH}$ and chromatin accessibility indicate that low-accessibility regions of chromatin tend to contain minimal amounts of $\mathrm{mCpH}$. The more-accessible genomic regions exhibit a proportional relationship between accessibility and $\mathrm{mCpH}$ content, while $\mathrm{mCpG}$ levels do not show this proportionality [40]. These data support the idea that $\mathrm{CpG}$ and $\mathrm{CpH}$ methylation are independently regulated.

DNA methylation is initiated and maintained by members of the DNMT family (DNMT1, DNMT3A, DNMT3B and DNMT3L) of DNA writers which methylate cytosine to form 5 -methylcytosine $(5 \mathrm{mC})$ (see Figure 1). DNMT1 is involved in maintaining the methylation status of $\mathrm{CpGs}$ during replication and is referred to as the maintenance methyltransferase. DNMTs $3 \mathrm{~A}$ and $3 \mathrm{~B}$, so-called de novo methyltransferases, initiate new methylation in most cell types [33]. In addition to methylating DNA, DNMT family members bind to DNA in association with additional proteins, such as $\mathrm{MeCP} 2$, forming stable repressor complexes [41,42]. Genome-wide mapping of the localization of DNMT proteins to DNA in human differentiated and undifferentiated cells show that each DNMT binds to discrete and overlapping intragenic regions depending on cellular differentiation status [41]. Interestingly, comparisons between the genome-wide locations of DNA methylation and DNMT binding suggest that DNMTs exert methylation-independent regulatory roles particularly in the vicinity of promoters and transcription start sites [41].
Cell-type specific patterns of methylation have been observed in different cortical brain regions and cerebellum using DNA isolated from postmortem human brain [43,44]. A large portion of differentially methylated regions (DMRs) are detected at or near genes that are selectively expressed across different brain regions [43]. Interestingly, it was noted in this study that $5 \mathrm{mC}$ is under-represented at classic $\mathrm{CpG}$ island containing promoters and enriched at intragenic CpG islands and promoters containing low levels of CpGs [43]. A more recent comparison of the DNA methylation profiles of four cortical regions, cerebellum, thalamus, hippocampus and pons showed that, with the exception of the cerebellum, DNA methylation patterns are far more homogeneous between different regions of the same individual, than they are for a single brain region between different individuals [45]. These studies show that while the mRNA profiles differ markedly in different brain regions, the methylation landscape does not. This study suggests that DNA methylation may not determine patterns of cell-specific gene expression as previously thought. By contrast, in the cerebellum, a strong inverse correlation was observed between gene expression profiles and DNA methylation data [45]. These studies present contrasting points of view regarding the role of DNA methylation in regulating the cellular phenotype. The differing conclusions could be related to the approaches used in producing the results of the respective studies. That is, one group used human DNA methylation microarrays $[43,44]$ while the second group used methyl-CpGbinding domain (MBD) affinity purification followed by deep-sequencing [45]. In both cases, only a fraction of the total sites in the genome that can be methylated are assayed. Moreover, both approaches do not provide adequate coverage of $\mathrm{mCpH}$ sites in the genome.

\section{DNA methylation readers}

Proteins that read methylated $(5 \mathrm{mC})$ and hydroxymethylated $(5 \mathrm{hmC})$ DNA bind these modified sequences through their evolutionarily conserved DNA-binding domains. Of the family of DNA methylation readers that bind methylated and/or hydroxymethylated DNA, MeCP2 is by far the most well studied. $\mathrm{MeCP} 2$ is $\mathrm{X}$-linked and is subject to $\mathrm{X}$ chromosome inactivation. It is genetically linked to the autism-related disorder Rett syndrome [46]. The purification, sequencing and cloning of $\mathrm{MeCP} 2$ from rat brain was first reported some 25 years ago [47,48]. The single polypeptide chain contains a methyl-binding domain (MBD) and a transcriptional repression domain [49-51]. Structural comparisons with other MBD proteins, including MBDs 1-4, support the idea that the MBD is common to proteins that recognize and bind methylated cytosines in DNA [52]. 


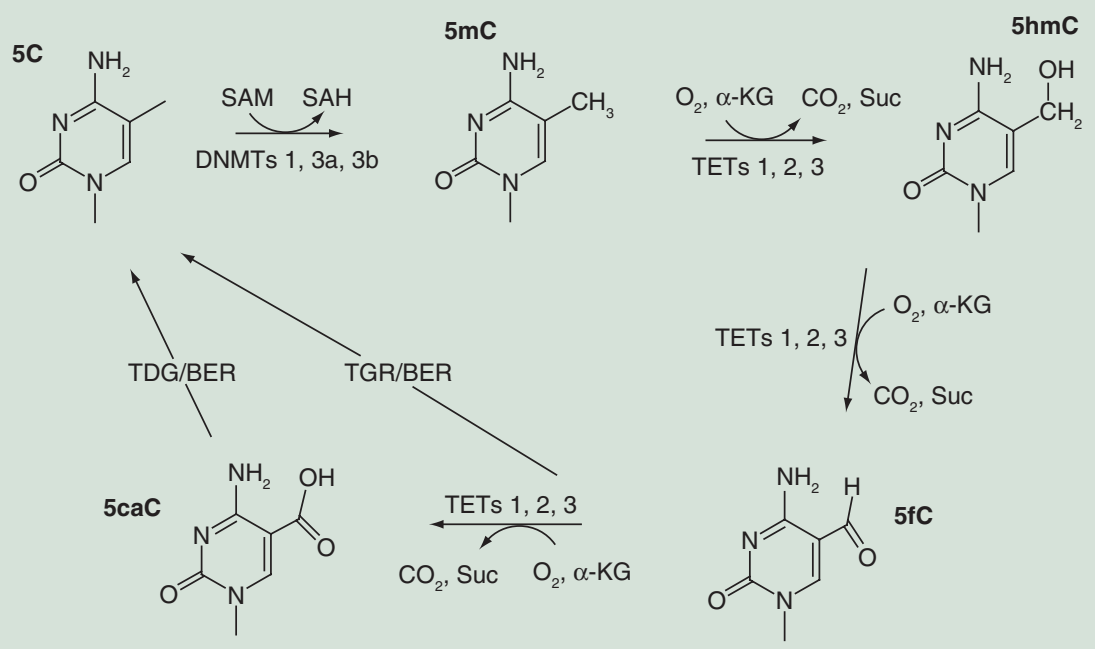

Figure 1. DNA demethylation pathway. DNA methylation, which utilizes the universal methyl donor SAM, is catalyzed by members of the DNMT family of proteins (DNMT 1, 3a and $3 \mathrm{~b}$ ). $5 \mathrm{mC}$ is a repressive chromatin mark that negatively correlates with gene expression. The demethylation of DNA, which re-activates transcription, occurs through several steps that involve the hydroxylation of the methylated cytosine. DNA hydroxymethylation, the first step in this cascade, is catalyzed by members of the TET (TETs 1-3) family of Fe(II)/ $\alpha$-ketoglutaratedependent dioxygenases. These enzymes further oxidize the hydroxymethyl group to form $5 \mathrm{fC}$ and $5 \mathrm{caC}$. Both $5 \mathrm{fC}$ and $5 \mathrm{caC}$ can be excised by TDG generating an abasic site which is subsequently replaced by BER enzymes regenerating the unmodified $\mathrm{C}$. The intermediates in DNA demethylation ( $5 \mathrm{hmC}, 5 \mathrm{fC}$ and $5 \mathrm{caC}$ ) accumulate to different extents in cells indicating that each epigenetic DNA mark is stable and likely serves a distinct function. This is thought to occur by the interaction of each modified base with a variety of DNA readers [86,87]. For example, unmodified cytosines $(5 \mathrm{C})$ are recognized and bound by proteins such as DNMT1 and TET1 that contain a -CXXC- motif in their zinc finger DNA-binding domain [42]. Methyl-binding domain proteins, like MeCP2 and other MBDs, bind to $5 \mathrm{mC}$.

BER: Base excision repair; SAM: S-adenosylmethionine.

For many years (as indicated above), methylation was thought to occur predominantly at CG dinucleotides, although, as noted above, $5 \mathrm{mC}$ had been found in $\mathrm{CA}, \mathrm{CT}$, $\mathrm{CC}$ (i.e., $\mathrm{CH}$, where $\mathrm{H}=\mathrm{A}, \mathrm{T}$ or $\mathrm{C}$ ) sequences as well [53,54]. Recent estimates of non-CG methylation in mouse and human indicate that levels of $5 \mathrm{mCH}$ in the brain are at least as high as $5 \mathrm{mCG}$ if not more so $[39,40]$. In addition, the TET family of proteins oxidize $5 \mathrm{mC}$ to form $5 \mathrm{hmC}$ (see Figure 1), which acts as a stable epigenetic mark in neurons [55]. These findings raise the possibility that $\mathrm{MeCP} 2$ and other methyl-CpG binding domain proteins bind to multiple methylated or hydroxymethylated dinucleotides other than $\mathrm{mCpG}$. But while $\mathrm{MeCP} 2$ has a high affinity for single symmetrically methylated CG dinucleotides, recent studies show that the MBD of MeCP2 also binds $\mathrm{mCH}$ with a strong bias for mCA [39,56]. In addition, it was also shown that the affinity of MeCP2 for $5 \mathrm{hmC}$ is considerably reduced relative to $5 \mathrm{mC}$. This result contrasts with previous findings that identified $\mathrm{MeCP} 2$ as the major $5 \mathrm{hmC}$-binding protein in the nervous system [57]. The recombinantly-expressed MBD of MeCP2 binds instead the rare hmCA modified dinucleotide [56]. Because of the low abundance of this modification in the neuronal genome, the significance of this finding is currently not clear. These findings challenge the concept that the MBD of $\mathrm{MeCP} 2$ binds both 5mCG and 5hmCG. However, MeCP2 may not strictly mimic the recombinantly expressed MBD and may exhibit altered binding properties when present as part of the native molecule.

As indicated above, $\mathrm{MeCP} 2$ is defective in a majority of Rett syndrome patients [46]. There is significant symptomatic overlap between Rett syndrome and ASD, including deficits in verbalization skills and loss of purposeful hand movements. While many Rett syndrome patients were initially diagnosed with ASD prior to genetic analysis, most do not meet DSM-5 diagnostic criteria for ASD [58]. Nevertheless, posmortem brains from both disorders show cellular abnormalities that include reductions in dendritic branching and cell soma size and reductions in the numbers of dendritic spines [59-61]. While the function of MeCP2 is primarily associated with neurons and astrocytes [62], the distribution of $\mathrm{MeCP} 2$ has been reported in a large number of cell types [63]. MeCP2 associates preferentially with methylated DNA and next-generation sequencing shows that its genome-wide binding 
tracks methyl-CpG density [64]. The $\mathrm{MeCP} 2$ primary transcript is alternatively spliced producing multiple (MeCP2E1 and MeCP2E2) isoforms. While both isoforms localize to neurons, astrocytes and oligodendrocytes, MeCP2E1 is relatively uniformly distributed in different brain regions, whereas MeCP2E2 shows differential enrichment in distinct brain regions [63]. Moreover, $\mathrm{MeCP} 2$ is differentially phosphorylated in an activity-dependent manner that is dependent on calcium $[65,66]$. Site specific phosphorylation of MeCP2 is known to impact both its binding to DNA and protein interaction partners such as CREB1, SIN3A, HP1 and SMC3 [67]. Moreover, activity-dependent phosphorylation alters $\mathrm{MeCP} 2$ function so that it orchestrates a genome-wide response to neuronal stimulation during nervous system development [68]. In addition to phosphorylation, $\mathrm{MeCP} 2$ has been shown to undergo additional post-translational modifications including acetylation, ubiquination and sumoylation (reviewed in [69]).

Mice deficient in MeCP2 in GABAergic neurons develop features reminiscent of ASD including stereotyped behaviors, deficits in social behavior, motor function, cognition and sensorimotor gating [70]. $\mathrm{MeCP} 2$ functions in cooperation with multiple chromatin repressors in binding to $5 \mathrm{mC}$, including the Sin3A repressor protein and HDACs [50,71]. Chromatin immunoprecipitation assays demonstrate that MeCP2, DNMT1, DNMT3a and HDAC2 bind to the same region of DNA of the GAD1 and RELN promoters in NT2 cells [72]. MeCP2 has a substantial role in modifying chromatin architecture. In addition to repressing gene transcription, gene dosage studies show that $\mathrm{MeCP} 2$ positively regulates the expression of a wide range of genes [73]. By associating with the transcriptional activator CREB1 and binding to cAMP response element-binding (CREB) sites at the promoters of activated targets [73]. In addition to Rett syndrome, MeCP2-mediated regulation of gene expression has been implicated in a wide number of neurodevelopmental disorders, including, as discussed below, ASD [74].

\section{DNA hydroxymethylation}

In addition to $5 \mathrm{mC}, 5 \mathrm{hmC}$ accumulates in the genome in mammalian cells (see Figure 1). The identification of $5 \mathrm{hmC}$ in cerebellar Purkinje and granule neurons of the cerebellum [75], and the demonstration that knockdown of ten-eleven translocase methylcytosine dioxygenases (TETs) reduce the amounts of cellular $5 \mathrm{hmC}$ levels [76] established a mechanism by which DNA methylation might be reversed. For many years, it was thought that the stability of the methyl group on the cytosine ring made DNA demethylation thermo- dynamically unfavorable. $5 \mathrm{hmC}$ is formed from $5 \mathrm{mC}$ by the enzymatic oxidation of the methyl group which is catalyzed by members of the TET (1-3) protein family. $5 \mathrm{hmC}$ is both an intermediate in DNA demethylation and a stable epigenetic mark that plays a role in various processes in the brain [77]. Moreover, $5 \mathrm{hmC}$ accumulates at promoters, gene bodies and distal regulatory elements [78,79]. It is thought that once converted to $5 \mathrm{fC}$ and $5 \mathrm{caC}$, the modified base is committed to demethylation by the action of thymine deglycosylase (TDG) [80]. Recent genome-wide maps of $5 \mathrm{hmC}$ in the brain have led researchers to attribute distinct functions to this modification depending on genic localization and local $5 \mathrm{hmC}$ density. That is, the function of $5 \mathrm{hmC}$ at distal regulatory elements called enhancers is different from its role within gene bodies or its role at mRNA splice sites. $5 \mathrm{hmC}$ is thought to impact transcription positively because it is located along the gene bodies of actively transcribed genes and it often also correlates with gene expression [81]. This is supported by data showing that the genome-wide location of $5 \mathrm{hmC}$ also negatively correlates with the location of two repressive chromatin marks, namely H3K27me3 and $\mathrm{H} 3 \mathrm{~K} 4 \mathrm{me} 3$ [82]. Having said this, it appears that the role of $5 \mathrm{hmC}$ may be even more complex [83]. Base resolution maps of $5 \mathrm{mC}, 5 \mathrm{hmC}, 5 \mathrm{fC}$ and $5 \mathrm{caC}$ show that there is a Tet-mediated gradient of $5 \mathrm{mC}$ oxidation state that correlates with enhancer activity [80]. This suggests that one role of the TET proteins is to facilitate enhancer activity during development from the fetus to the adult [81].

As indicated in Figure 1, the TET proteins further oxidize $5 \mathrm{hmC}$ to form $5-\mathrm{fC}$ and $5-\mathrm{caC}$, both of which are also stable epigenetic marks that accumulate in the brain across the genome $[84,85] .5 \mathrm{hmC}$ interacts with a large number of distinct nuclear proteins that recognize and read this epigenetic mark both in embryonic stem cells and in adult brain $[57,86,87]$. The $5 \mathrm{hmC}$ oxidation product, $5 \mathrm{fC}$, is also read by a diverse set of proteins that include transcriptional regulators, DNA repair factors and chromatin regulators [87]. Both $5 \mathrm{fC}$ and $5 \mathrm{caC}$ (Figure 1) are specifically bound by TDG, which catalyzes the formation of abasic sites that are subsequently repaired by enzymes of the base excision repair (BER) pathway producing unmodified cytosine [88-90]. DNA demethylation via TET-mediated oxidation occurs in the brain in response to depolarization. Some 3000 CpG sites undergo active DNA demethylation in dentate granule neurons following synchronous neuronal activation [91]. The demethylated CpGs are located at or proximal to neuronal-specific genes implicated in neuronal plasticity [91]. The simultaneous activation of multiple genes by DNA demethylation in response to depolarization allows for an orchestrated transcrip- 
tional response as an adaptation or plasticity program of the neuron. While many studies of TET proteins in the CNS have focused on TET1, TET3 was recently shown to act as a sensor of synaptic activity in the brain and to regulate surface levels of GluR1 in response to synaptic activity [92]. It is now recognized that all three TET proteins serve distinct functions in the brain and that neuronal differentiation is accompanied by increased levels of all three TETs.

\section{DNA methylation in ASD}

Female patients heterozygous for mutations in the X-linked methyl DNA-binding protein MECP2 are highly likely to exhibit symptoms of Rett syndrome. Because of the symptomatic overlap between Rett syndrome and ASD, DNA methylation would seem to be a likely mechanism associated with the pathogenesis of ASD. In addition, recent studies support the concept that epigenetic factors converge on DNA methylation as a consequence of environmental factors that are relevant to ASD. Studies of single ASD gene candidates provide evidence of altered methylation at multiple genes including BCL2 [93], EN2 [94], MeCP2 [95,96], OXTR [97], RORA [93], SHANK3 [98] and UBE3A [99]. While these candidate gene studies support a role for methylation in ASD, it is as yet unclear as to what may be causing these changes and why these particular genes are targeted.

In contrast, data from genome-wide DNA methylation studies have produced mixed results. A genomewide methylation analysis of DNA from cerebella and cortices (Brodmann area 9 [BA9]) of ASD subjects versus matched typical developing controls found no significant differences in DNA methylation between groups [100]. This study was performed using the Illumina HumanMethylation27 BeadChip, which measures upwards of 27,000 probes across the genome. A second study independently reported results from multiple brain regions (dorsolateral prefrontal cortex, temporal cortex and cerebellum) of 20 ASD and typically developing controls using the updated Illumina HumanMethylation450 BeadChip. They identified multiple DMRs [101]. Positive results within each tissue were subsequently validated. The DMRs in the temporal cortex were proximal to the following genes: PRRT1, TSPAN32/C11orf21 and ZFP57. In cerebellum SDHAP3 was identified [101]. The DMRs are interesting and biologically diverse. PRRT1 is thought to be expressed primarily in the hippocampus and is a component of the outer core of the AMPAR complex. This DMR may be important in regulating the expression of the corresponding gene [102]. A second DMR identified in this study is located in a region that overlaps TSPAN32 and C11orf21. While the func- tion of the C11orf21 protein is not known, TSPAN32 appears to be a scaffolding protein important for cellular immunity [103,104]. ZFP57 is important for DNA imprinting marks during development $[105,106]$ and recruits DNMTs [107]. Finally, the DMR identified in cerebellum is located on a CTCF binding site and active regulatory element associated with a noncoding RNA and a small coding RNA. It is also an alternative promoter of SDHAP3 which is involved in succinate metabolism. Analysis of whole blood DNA from MZ twins discordant for ASD identified numerous significant DMRs, including many in genes previously implicated in ASD. These DMRs are widespread and correlate with autistic trait scores [108]. The specific sites that have been identified thus far support a role for aberrant DNA methylation in ASD brain and blood and provide insight into novel genes dysregulated in ASD.

The most recent methylation array analysis of ASD compared two cortical regions, BA24 and BA10, and also used the HumanMethylation 450 BeadChip [109]. Like the previous two studies [100,101], these authors report data using a small set of postmortem ASD and control brain. In BA10, over $5329 \mathrm{CpG}$ sites were detected as differentially methylated and 10745 CpGs were identified as differentially methylated in BA24 [109]. Interestingly, neurotypical controls exhibit over 50,000 DMRs between these brain regions. The same comparison between ASD brain regions (i.e., BA10 vs BA24) showed only approximately 10,000 DMRs [109]. Only a small percentage of hypomethylated $(3.5 \%)$ or hypermethylated (5.9\%) DMRs corresponded to previously identified autism candidate genes. Of particular interest is the finding that of the significant DMRs identified in ASD, many of these were associated with immune response genes, including leukocyte migration, cytokine biosynthesis and the inflammatory response. Many of the DMRs related to immune functions are hypomethylated and correlate with increased transcription. In contrast, genes relevant to synaptic membrane function are hypermethylated and correlate with decreased expression. These data highlight an important area of investigation that is receiving attention in the literature (see transcriptomic studies discussed above). That immune response genes are enriched in the hypomethylated gene set suggests a dysregulated immune system as a potential etiological factor. Many of the same 'immune' genes are not also observed in the positive findings identified by genetic studies supporting the concept that these genes are likely induced through an environmentally-mediated epigenetic mechanism. In DNMT1/DNMT3A knockout mice, immune response genes are disproportionately represented as differentially methylated [110]. Maternal hospitalization due to viral infection is one of the environmental factors reported 
to increase risk of ASD [111-113]. These studies add to the growing literature, encompassing both animal and human studies that support possible immune responsemediated epigenetic mechanisms as potential etiological factors in ASD.

The genome-wide methylation studies indicated above [101,109] differed with respect to their findings regarding methylation and ASD. Reasons for these differences could be due to differences in the methylation detection platform or in the means of processing the methylation data. However, both groups used the same detection platform, in other words, the HumanMethylation 450 BeadChip. This platform covers over 485,000 CpGs and so has a much broader coverage than the HumanMethylation27 array. However, it should be noted that while the $450 \mathrm{k}$ BeadChip covers over $99 \%$ of known RefSeq genes, there is only limited coverage of non-CpG sites (i.e., $\mathrm{CpH}$ sites). In addition, the $450 \mathrm{k}$ BeadChip covers only about $2 \%$ of the total CpG sites in the human genome $(\sim 28,000,000[114])$, and there are areas that are poorly represented (e.g. introns and intergenic regions) that are enriched in DMRs. One potential reason for the observed differences may be the different in silico analytical tools used in evaluating the methylation array data. It should be noted that results from the earlier study [101] were also examined in the later one [109]. Many of the sites previously identified, including CpGs sites upstream of C11orf21/TSPAN32, were also positive in the second study. Aside from technical issues related to data processing, there may also be issues related to cellular composition in postmortem tissue samples [115], as well as differences between patient/control cohorts. It should be noted that in both studies, sample sizes were relatively small. In addition, the HumanMethylation450k BeadChip does not differentiate between $5 \mathrm{mC}$ and $5 \mathrm{hmC}$ unless the conventional methodology is modified. With the recent advances that have occurred in the identification and sequencing of modified cytosines, complete coverage of the human genome at base resolution should be considered a necessity [83]. This is particularly important as we uncover new functions associated with large numbers of non-coding genes likely involved in different types of gene regulation. While a great deal of new information is available regarding genomic locations of $5 \mathrm{mC}$ and $5 \mathrm{hmC}$ in adult brain [82], much less is currently known regarding how changes in the levels of $5 \mathrm{hmC}$ at specific sites are facilitated and how these modifications are targeted to specific sites.

\section{DNA hydroxymethylation in ASD}

As noted above, $5 \mathrm{hmC}$ is abundant in the developing nervous system with levels increasing markedly between the fetus and adult brain [82]. However, there is currently little information available regarding DNA hydroxymethylation and ASD in structures other than the cerebellum. The dynamics of DNA hydroxymethylation were recently examined using immuneprecipitation of $5 \mathrm{hmC}$ from DNA isolated from fetal and adult human brain [116]. This group reported that while $5 \mathrm{hmC}$ is highly enriched at specific DNA domains including exons and untranslated regions, it is depleted at introns and intergenic regions. In addition, the amounts of $5 \mathrm{hmC}$ were noted to increase during cerebellar development with the largest amounts present in the adult. Moreover, differentially hydroxymethylated regions (DhMRs) were shown to overlap within highly expressed genes and $\mathrm{CpG}$ island shores. Interestingly, $5 \mathrm{hmC}$ was enriched at mRNAs that are regulated by the fragile X mental retardation protein (FMRP), as well as many genes linked to neurodevelopment and ASD [116].

We recently examined epigenetic mechanisms underlying the regulation of several candidate genes in cerebella of ASD subjects. We studied the expression of several enzymes in the DNA methylation/hydroxymethylation pathway, regional amounts of $5 \mathrm{mC}$ and $5 \mathrm{hmC}$, and the expression of various ASD candidate genes in cerebellum of ASD subjects [117]. Our data showed that DNMT1 mRNA is unchanged and TET1 mRNA is increased in cerebella of ASD postmortem subjects. Moreover, the increase in TET1 is accompanied by enriched amounts of $5 \mathrm{hmC}$ in the promoters of GAD1 and RELN. While no changes were detected in $\mathrm{MeCP} 2$ protein levels, increased binding of $\mathrm{MeCP} 2$ to the same RELN and GAD1 promoter DNA stretch was noted. While there were no measurable differences in DNMT mRNA levels or in the binding of DNMT1 to the RELN and GAD1 promoters, the increased expression of TET1 was accompanied by increased binding of TET1 protein to these promoters [117]. Moreover, the study showed that increased amounts of $5 \mathrm{hmC}$ in promoter proximal domains negatively correlate with GAD1 and RELN mRNA levels in ASD cerebella. As opposed to the study cited above [116], our finding supports a negative role for increased $5 \mathrm{hmC}$ levels and expression of the corresponding gene.

A recent paper described results obtained in a similar candidate gene study of EN2 in a cohort of ASD cerebella [18]. These investigators examined DNA modifications in the context of the regulation of EN2. Like the previous paper, they show increased levels of not only TET1, but also TET3, DNMT3A and DNMT3B. Increased amounts of $5 \mathrm{hmC}$ were observed at the EN2 promoter which correlate with increased EN2 mRNA expression [118] rather than decreased expression, as noted with RELN and GAD1 [117]. In addition, the increased levels of $5 \mathrm{hmC}$ at EN2 were associated with decreased levels of MeCP2 binding to the corresponding promoter sequences. MeCP2 binding has been 
reported to be dependent on total $5 \mathrm{mC} / 5 \mathrm{hmC}$ content and additional factors such as the local histone modifications [57]. The discrepancy in terms of $\mathrm{MeCP} 2$ binding relative to $5 \mathrm{mC}$ and $5 \mathrm{hmC}$ in these two studies is not clear although could be the consequence of various post-translational modifications.

Similar to what was reported in cerebella of ASD patients [117], the levels of RELN and GAD1 mRNA are also reduced in the frontal cortices of ASD and control postmortem brain [119]. There is a concomitant increase in TET1-3 expression, a decrease in DNMT1 and MeCP2 mRNA levels are unchanged in the frontal cortex in the same patient cohort. We also report that MeCP2 and DNMT1 binding to the RELN and GAD1 promoters is increased. At the same time, the levels of $5 \mathrm{mC}$ in the corresponding promoter regions decrease while the levels of $5 \mathrm{hmC}$ are not statistically different. The $5 \mathrm{hmC} / 5 \mathrm{mC}$ ratio at both promoter regions is higher and negatively correlates with transcription. The finding of increased MeCP2 binding and reduced amounts of DNA methylation in the same stretch of DNA is difficult to reconcile. However, DNMT1 has been shown to interact with the transcriptional repressor domain of $\mathrm{MeCP} 2$ [120]. It may be that DNMT1, through protein-protein interactions with $\mathrm{MeCP} 2$, drives the increased binding of a DNMT1:MeCP2 repressor complex to unmethylated cytosines through the DNMT1 -CXXC- domain [121]. Biochemical studies demonstrate that $\mathrm{MeCP} 2$ assembles novel repressive chromatin structures independent of DNA modification [122]. Another possibility is that recognition of $5 \mathrm{mC}$ by the $\mathrm{MBD}$ of $\mathrm{MeCP} 2$ is facilitated by chromatin compaction [122]. Additional studies are needed to better understand how $5 \mathrm{hmC} / 5 \mathrm{mC}$ levels change genome-wide, and how this measure impacts $\mathrm{MBD} / \mathrm{MeCP} 2$ and DNMT protein binding and gene transcription.

\section{Environmental effects}

Environmental factors induce perturbations to the epigenome during critical periods of neurodevelopment, which affect cells during processes of proliferation, migration and terminal differentiation. As indicated above, at the molecular level these perturbations include changes in DNA methylation, hydroxymethylation, histone modifications and the expression of various noncoding RNAs. Reviews describing associations between environmental factors and ASD have been published in recent years [74,123-128]. However, considerably less is known regarding the mechanisms by which these factors impact the epigenome. Vast amounts of monies have been expended on identifying genes associated with ASD. We now need to invest in research that provides a better understanding of mech- anisms by which environmental factors influence gene expression profiles at both the molecular and circuit levels so that we can better appreciate their effect on brain development. Below we discuss the role of maternal stress, infections and prenatal nutrition because considerably more is known regarding the effect of these factors on the epigenome.

\section{Maternal stress}

Fundamental processes facilitating changes in gene expression in response to environmental or extracellular cues include DNA and histone modifications (Figure 2). There is ample evidence to suggest that environmental factors related to the response of the brain to pre- or postnatal stress/trauma increase risk for ASD. Numerous studies have reported an association between prenatal stress and the development of autistic traits [129], and increased ASD risk [130]. The effects of prenatal stress via maternal factors crossing the placenta influence a wide range of neuronal and nonneuronal systems during fetal development depending on gestational timing. Recent evidence indicates that neuronal circuit formation in the brain is susceptible to the effects of prenatal stress. The establishment of GABAergic inhibitory circuits occurs at times when prenatal stress exerts persistent effects on the brain and behavior [130]. Prenatal restraint stress has been shown to delay tangential migration of interneuron progenitors in rodents [131]. Prenatal stress exerts a profound epigenetic influence on GABAergic interneurons by altering the levels of proteins such as DNMT1 and Tet1 and decreasing the expression of various targets such as BDNF [132,133]. Ultimately, this results in reducing the numbers of fully functional GABAergic neurons postnatally and a concomitant increased susceptibility toward hyperexcitability. The delayed migration of GABAergic interneuron progenitors results in reduced gene expression postnatally which is likely the consequence of increased amounts of DNA methylation [133]. In mice, mutations targeting the Plaur gene disrupt the ontogeny of the forebrain by arresting migration of inhibitory parvalbumin interneurons from the medial ganglionic eminence [134]. Parvalbumin-expressing interneurons have also been implicated in transcriptomic studies of postmortem ASD brain $[25,135]$, and in the autism-like behavioral deficits exhibited by Pvalb knock-out mice [136]. The downstream effectors of the stress response, glucocorticoids, have also been shown to retard the radial migration of postmitotic neurons during cortical development [137]. The net effect of stress during early development is to disrupt the balance of excitatory/inhibitory neuronal firing due to the loss of function associated with disrupted neuronal migration and maturation. 


\section{In utero environment}

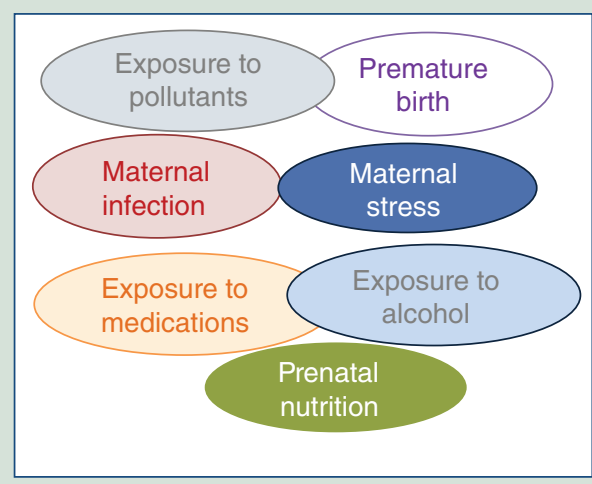

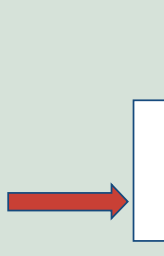

Altered epigenome

Altered expression of genes encoding epigenetic proteins
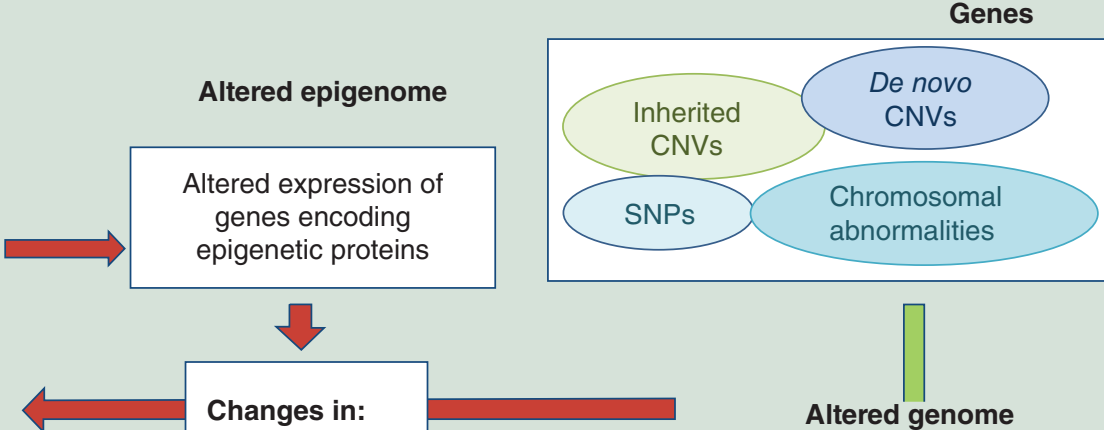

Changes in:

$-5 \mathrm{mC}$

$-5 \mathrm{hmC}$

$-5 f C$

$-5 \mathrm{caC}$

- acH3/acH4

- $\mathrm{meH} 3 / \mathrm{meH} 4$

- miRNAs

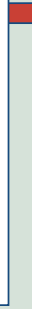
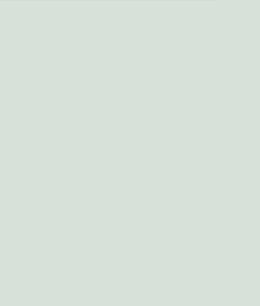

Altered genome

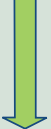

Network

hub genes

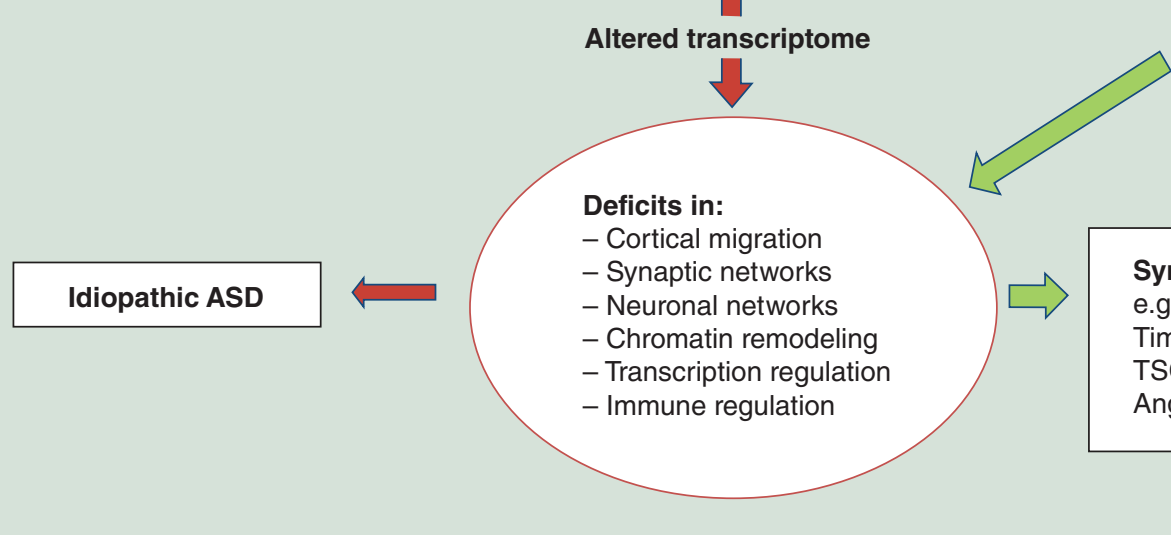

Figure 2. Epigenetic impact of the prenatal environment. Environmentally induced epigenetic mechanisms acting on the genome during prenatal and early postnatal development facilitate genome-wide changes in the epigenome that alter transcription at distinct developmental time points. The mRNA alterations that occur cause deficits in multiple processes including cortical migration, chromatin remodeling, transcriptional regulation, immune-response regulation and the formation of synaptic connections. Genome-wide association and whole exome sequencing studies have identified a large number of genes linked with ASD that encode proteins that function in synapse formation, transcriptional regulation and chromatin-remodeling pathways [12]. Current findings, highlighted in this review, indicate that there is considerable overlap between ASD-susceptibility genes and the mRNAs impacted by various environmental/epigenetic influences. Both environmental factors and genetic mutations alter the transcriptome during neurodevelopment. We propose that idiopathic ASD is the consequence of environmentally induced epigenetic influences operating on sufficient numbers of ASD susceptibility genes to produce the ASD phenotype. Individuals with mutations in ASD susceptibility genes are also subject to these same in utero environmental influences (arrow from altered genome). In contrast, syndromic ASD is characterized by genetic mutations that occur in so-called network hub genes [25]. In network theory, hub genes refer to highly interconnected nodes that are often times responsible for regulating key biological pathways or directing the cellular response to a given stimulus [185]. For example, FMR1 encodes the RNA-binding protein, FMRP which is deficient in Fragile X, an ASD-related syndrome. FMRP regulates the translation of a set of over 800 plasticity-related genes in response to stimulation by the neurotransmitter glutamate [186]. Mutations in FMR1 cause Fragile X syndrome, which is a syndromic ASD. The etiology and symptomatology of various syndromic ASD disorders has recently been reviewed $[8,9]$.

ASD: Autism spectrum disorder; CNV: Copy number variant.

\section{Maternal infections}

Immune system dysfunction plays an important role during neurodevelopment and has been implicated in ASD symptoms. This includes findings of neuroinflammation, presence of autoantibodies, increased T-cell responses, increased natural killer cell responses and monocyte responses in ASD subjects [138]. More- over, there are also reports of cytokine dysregulation in ASD which is likely the consequence of altered immune system activity [139]. Transcriptome studies of ASD brain provide data demonstrating that mRNAs associated with activated microglial and immune response genes are altered relative to non-ASD brain $[20,25]$. As noted above, an independent methylation analysis of 
ASD brain samples shows that genes associated with immune system function tend to be hypomethylated compared with DNA isolated from non-ASD brain samples [109]. This is consistent with the increased mRNAs observed in the transcriptome studies $[20,25]$. Alterations in the expression of genes that function in immune-glial response pathways are likely the consequence of prenatal maternal infections or neuroinflammation (see [140] for recent review). This is supported by recent reports showing that increased risk for ASD correlates with maternal inpatient diagnosis with infection during pregnancy [111-113,141,142]. These findings are also consistent with observations that children with ASD report numerous immune system irregularities including inflammation [143,144]. Immunological factors, including inflammation, autoimmunity and maternal immune activation have long been suspected in the context of aberrant neurodevelopment and ASD risk (see $[140,145]$ for current reviews). A recently published proof of concept study was undertaken to examine genome-wide RNA expression profiles in leucocytes from cohorts of children ages 1 to 4 years looking for gene modules as potential ASD biomarkers [146]. The authors report strong significant dysregulation of immune and inflammatory gene networks at an age where clinical risk signs of ASD are first beginning to emerge [146]. The finding that immune system dysfunction may be an important causative factor in ASD also provides a link to schizophrenia, another neurodevelopmental disorder that shows some overlap with respect to de novo mutations [147], and has been etiologically linked with maternal immune activation [148]. The risk for both schizophrenia and autism has been linked epidemiologically to maternal infection $[111,149]$.

\section{Prenatal nutrition}

The maternal lifestyle during gestation can expose the fetus to a wide range of environmental insults and influences $[123,125]$. These include nutritional choices of the mother that directly impact neurodevelopment of the fetus and which been shown to influence epigenetic mechanisms [124,150]. Maternal nutrition is essential for fetal brain development and nutritional deficiencies due to increased metabolic demands imposed by the placenta and fetus during pregnancy are linked to neurodevelopmental disorders. The most direct association between nutrition and epigenetics occurs through pathways that involve methyl transfers, such as DNA and histone methylation, which utilize the methyl donor $S$-adenosyl-methionine (SAM). Early alterations in DNA methylation can cause cells to aberrantly differentiate from their normal lineage causing abnormal pools of differentiated neurons [151]. DNMTs utilize SAM to donate methyl groups at specific sites in DNA [33]. Similarly, histone methyltransferases (HMTs), which have been genetically linked to various psychiatric disorders [152], catalyze the transfer of up to three methyl groups to the e-amino group of specific lysines on histones $\mathrm{H} 2$ (H2BK5), H3 (H3K4, H3K9, $\mathrm{H} 3 \mathrm{~K} 27$ and H3K79) and H4 (H4K20). The levels of SAM available for one carbon transfers are affected by methyl groups derived from dietary choline, methionine and methyl-tetrahydrofolate. Folate is a major source of the methyl group for SAM and is readily available for pregnant women as part of a periconceptual vitamin supplement. A large case-control study provides epidemiological data showing that mothers of ASD children consumed less folic acid than mothers of typically developing children [153]. Based on results from this study, a greater risk of ASD was observed for children whose mothers had defects in genes associated with one carbon metabolism [153]. Subsequently, this group also reported that there is an inverse correlation between folic acid intake and ASD risk [154]. The finding that periconceptional folic acid supplementation is associated with a lower risk of ASD was replicated in a large Norwegian cohort of over 85,000 children [155]. The folic acid contained in these formulations is sufficient for both the prevention of neural tube defects and to ensure an adequate supply of methyl donors preceding and during gestation. Folic acid and prenatal vitamin supplementation protect against a range of human cancers, neurodevelopmental and neurodegenerative disorders [126]. A model was recently proposed that explains how exposure to a wide range of environmental toxins that impact neurodevelopment also result in global DNA hypomethylation [156]. This model was extended to connect pathways between dietary nutrition and environmental exposures in the context of DNA hypomethylation [157]. More recently, this hypothesis was expanded to show how dietary nutrients, environmental toxins, genome instability and neuroinflammation interact to produce changes to the DNA methylome [126].

In addition to folic acid, there is evidence that children of mothers that have a higher intake of polyunsaturated fatty acids before and during pregnancy have a reduced risk of ASD [158]. Vitamin D is a fat-soluble steroid hormone that regulates large numbers of genes that impact the brain during development. The levels of vitamin $\mathrm{D}$ are low in populations living in overcast areas that have low sun exposure. The number of ASD diagnoses in regions with low sun exposure in the USA is increased and has also been linked to vitamin D insufficiency [159]. Recent studies show that vitamin $\mathrm{D}$ activates the expression of tryptophan hydroxylase, the enzyme associated with serotonin synthesis [159]. This is particularly interesting because 
it links findings showing decreased levels of serotonin in ASD patients [160] and reduced levels of vitamin D. However, a previous study found little evidence that maternal gestational vitamin $\mathrm{D}$ levels are related to the ASD phenotype among offspring [161]. In addition, while there is evidence that vitamin D may increase DNA demethylation of selected gene promoters, the mechanisms behind this effect are not clear [162]. There is stronger evidence that vitamin $\mathrm{D}$ acts to modulate chromatin access through interactions with histone acetyltransferases [162]. Moreover, aside from activating vitamin $\mathrm{D}$ responsive genes through a coactivator mediated pathway, the means by which vitamin $\mathrm{D}$ facilitates changes in chromatin relaxation are only beginning to be understood.

\section{Exposure to air pollution, pesticides, prenatal valproate, cell phone radiation \& ASD}

Environmental toxins that are associated with negative health consequences have been shown to impact neurodevelopment and have been implicated in ASD [123]. For example, exposure to traffic-related air pollution, nitrogen dioxide and particulate matter during pregnancy and the first year of life is associated with ASD [163]. Toxicants that are associated with increased ASD risk include pesticides, phthalates, polychlorinated biphenyls, solvents, toxic waste sites, heavy metals and air pollutants [164]. An epidemiological study has linked PVC flooring material in the home to parental-reported ASD [165]. Exposure to plasticizers, such as bisphenol-A, results in higher levels of metabolites excreted in urine [166].

Respiratory distress and other markers of hypoxia have been associated with increased risks of ASD in twins [167]. Early exposure to androgenic hormones and maternal immune response represent epigenetic factors that affect sex susceptibility to ASD [168]. Residential proximity to agricultural pesticides during pregnancy is associated with increased risk of ASD and developmental delay [169]. The histone deacetylase inhibitor and antiepileptic drug, valproate, has long been known to cause congenital malformations and developmental delay in children exposed during gestation. In addition, maternal use of valproate to treat epilepsy during pregnancy is associated with significantly increased risk of ASD [170]. Finally, mice exposed to low frequency electromagnetic fields show a lack of normal sociability and preference for social novelty while maintaining otherwise normal behaviors [171]. While these studies show associations and links between factors in the environment and ASD, much less is known regarding how exposure to these developmental influences trigger changes to the epigenome.

\section{Conclusion}

Genetic studies have revealed a plethora of genes that are associated with increased ASD risk. It is well known that patients diagnosed with ASD exhibit considerable variability in both the number and severity of symptoms. Because of the genetic and symptomatic heterogeneity, ASD is also thought to be etiologically heterogeneous. However, as recently argued [19], neuropathological findings in both idiopathic and syndromic ASD support instead a common pathophysiological mechanism. The author of this study argues that multiple exogenous and endogenous factors disrupt cell division in the brain which leads to the pathological changes observed in ASD. These changes are thought to be related to alterations in cortical columnar structure, in dendritic spines and within the cortical subplate [172] manifest as various dysplasias and heterotopias [173]. In addition to these cortical malformations, environmental factors that contribute to neurodevelopment by altering folate metabolism, modifying the stress and inflammatory responses, and disrupting neuroendocrine hormonal signaling were also discussed [174]. In other words, both genetic mutations and environmental stressors impact neurodevelopment by altering the expression of modules of genes in multiple cell types.

Transcriptome studies of postmortem brain indicate that the expression of numerous genes and hence multiple pathways are disrupted in ASD pathophysiology (Figure 2). This includes pathways associated with synaptic and neuronal function (neuronal growth, migration, dendritic and neurite outgrowth, synaptic plasticity), chromatin remodeling (DNA $5 \mathrm{mC}$ and $5 \mathrm{hmC}$ writers, readers and erasers; histone writers, readers and erasers; chromatin remodeling proteins; microRNA expression) and immune function (microglial activation states). An overlapping set of genes associated with these pathways have also been identified in genetic studies of ASD. Immune function genes are the exception as the expression of these genes is likely a consequence of infection or neuroinflammation and not due to genetic mutation [175]. Moreover, mRNA changes linked to immune function genes tend to be increased rather than decreased in ASD [20]. It seems clear that both DNA mutations and environmental factors impact development in similar ways by reducing the expression of key genes associated with typical development. That is, the overlap between genes identified by genetic and transcriptomic studies supports observations that genes associated with synaptic function and chromatin remodeling are disrupted in ASD and related neurodevelopmental disorders. Loss-of-function mutations are syndromic when multiple downstream pathways are affected, as occurs in Fragile X and Rett syndromes (Figure 2). The disrup- 
tion of hub (multiconnected) genes impacts multiple downstream pathways. Instead, environmental factors, which also reduce the expression of multiple genes that impact downstream pathways, often result in idiopathic ASD. This could be due to the less severe developmental effects caused by reducing gene expression, as opposed to a complete loss of function. As we move forward in defining the causative factors of ASD, it will be important to invest in research designed to fill the void in our current understanding of how individual environmental factors impact epigenetic marks across the genome. Organizations (both governmental and private) that fund ASD studies need to invest both in epigenomic and genetics research.

In the context of this review, we have discussed numerous advances that have been made in ASD research in recent years. As noted, however, ASD is comorbid with multiple additional conditions including various seizure disorders and ID. Although there is considerable overlap between ASD and ID, intellectual disability is often considered separately from ASD. This is not surprising given that there are people with ASD or ID and people that experience both ASD and ID. It is not surprising that recent genetics studies of ID have identified CNVs that are often times also present in subjects with ASD [176]. One of the problems that these issues raise is that current estimates of autism prevalence do not always account for the effects of comorbidity on the ASD diagnosis [177]. In fact, at one point it was speculated that much of the recent advances in ASD research have been the result of research on subjects who are intellectually normal [7]. While it is not clear if this remains to be a problem, it is incumbent upon researchers reporting results to provide accurate, clear and anonymous clinical descriptions of the subjects in their studies.

\section{Future perspective}

Transcriptome analyses of ASD postmortem brain tissue demonstrate that large numbers of mRNAs are altered as compared with age- and gender-matched typically developing subjects. A recent meta-analysis of transcriptome studies in ASD confirmed that there are commonalities across independent groups of individuals with ASD [178]. The mRNA changes are the consequence of gene mutations (SNPs, de novo and inherited CNVs, chromosome abnormalities) that impact the associated gene and environmental factors that influence the epigenome during neurodevelopment (see Figure 2). While the immediate consequences of null mutations may be predicted, the downstream consequences of these mutations are more difficult to predict. For example, a mutation in GRIN2B has the immediate consequence of disrupting GRIN2B mRNA and protein levels. Downstream consequences of this mutation impact the expression of genes associated with numerous signaling cascades ( $\mathrm{p} 53$, JakSTAT, Wnt and Notch pathways), as well as, the actin cytoskeleton and neuroactive ligand-receptor interactions [179]. In order to better understand the complex interconnections that underlie ASD-related phenotypes, we have to better appreciate how multiple gene networks overlap and the connections within each network. These studies are currently underway and some have appeared in the literature [179-183]. That is, we are currently at the point in which genes within networks show nonquantifiable relationships and it would be more informative to be able to weight the contributions of individual genes to nodes within networks to allow for quantitative predictions to be made.

Currently available data suggest that there is overlap between mRNAs misregulated in ASD due to genetic abnormalities [12,13,15,184], and the mRNAs differentially expressed derived from transcriptome studies of ASD subjects $[20,25]$. Epigenetic modifications likely converge on specific sets of genes depending on the nature of the environmental factor. Moreover, while numerous studies have been carried out on environmental factors in specifying ASD-related phenotypes [124-126,158]), considerably less is known regarding the direct consequences of these factors on the epigenome. Some environmental factors increase DNA methylation (as in synaptic plasticity genes), while others likely facilitate DNA demethylation (immune function genes) and others likely affect histone methylation and acetylation patterns. Ultimately, transcriptomic profiles reflect the downstream consequences of the effects of genetic mutations/abnormalities and environmental factors and how these forces interact during neurodevelopment. Understanding how the epigenome responds to environmental insults will likely provide better insight into common final pathways operative in the pathophysiology of ASD and provide for the design of better pharmacotherapeutic treatments.

\section{Financial \& competing interests disclosure}

This work was supported by NIH grant 5R01 MH093348 (to A Guidotti). The authors have no other relevant affiliations or financial involvement with any organization or entity with a financial interest in or financial conflict with the subject matter or materials discussed in the manuscript apart from those disclosed.

No writing assistance was utilized in the production of this manuscript.

\section{Open access}

This work is licensed under the Attribution-NonCommercialNoDerivatives 4.0 Unported License. To view a copy of this license, visit http://creativecommons.org/licenses/by-nc$\mathrm{nd} / 4.0 /$ 
Executive summary

Autism spectrum disorder genetics

- Data from genetic studies have been used to identify a large number of genes that contribute increased risk for autism spectrum disorder (ASD). Network analysis of these genes indicate that they converge on a small set of pathways that are integral to synaptic function, chromatin remodeling and transcriptional regulation.

Transcriptome profiles in ASD brain

- RNA-seq studies have provided information regarding transcriptome changes in various brain regions of ASD subjects as compared with typically developing individuals. Network correlation analysis of these mRNAs provides evidence that in addition to ASD risk genes, modules of genes associated with immune function, synaptic transmission and neuronal function are altered in ASD.

DNA methylation in ASD

- Members of the DNMT and TET family of proteins modify DNA by either adding a methyl group or by oxidizing the methyl to form $5 \mathrm{hmC}, 5 \mathrm{fC}$ and $5 \mathrm{caC}$. Changes in the levels of $5 \mathrm{mC}$ and $5 \mathrm{hmC}$ have been noted at specific genes in brains of subjects diagnosed with ASD. Comparisons of genome-wide DNA methylation data with transcriptome data in ASD show that genes associated with immune regulation are hypomethylated and overexpressed, while genes related to synaptic function are hypermethylated and underexpressed.

DNA methylationreaders

- Members of the methyl binding domain family of proteins, which includes the Rett syndrome protein, $\mathrm{MeCP} 2$, bind to $5 \mathrm{mC}$ residues. While MeCP2 is ubiquitously expressed in neurons and astrocytes it localizes to repressed chromatin domains facilitating transcriptional silencing.

DNA hydroxymethylation in ASD

- DNA hydroxymethylation is the first step in the DNA demethylation cascade. Changes in the levels of $5 \mathrm{hmC}$ in ASD postmortem brain have not been widely studied. Thus far, the research has focused on ASD candidate genes and results show that the increased $5 \mathrm{hmC}$ is associated with both increased (En2) and decreased (RELN, GAD1) mRNA expression. This suggests the possibility that the $5 \mathrm{hmC}$ epigenetic marks may be inappropriately read by the transcriptional machinery.

Environmental effects

- Exposure to various environmental factors, including stress, infections, nutrition, substance abuse, medications, pollutants and toxins have been linked to increased ASD risk. These factors are likely to impact the epigenome through changes in DNA methylation and related mechanisms that regulate local chromatin conformation. Collectively, the current literature suggests that the effects of environmental factors converge on epigenetic pathways that result in altered $5 \mathrm{mC}$ and $5 \mathrm{hmC}$ marks. There is a growing need to better understand how each of the environmental influences impact chromatin structure in neurons, astrocytes and microglia of the brain.

\section{References}

Papers of special note have been highlighted as: $\bullet$ of interest

1 Frazier TW, Georgiades S, Bishop SL, Hardan AY. Behavioral and cognitive characteristics of females and males with autism in the Simons Simplex Collection. J. Am. Acad. Child Adolesc. Psychiatry 53(3), 329-340 e321-323 (2014).

2 Lane AE, Molloy CA, Bishop SL. Classification of children with autism spectrum disorder by sensory subtype: a case for sensory-based phenotypes. Autism Res. 7(3), 322-333 (2014).

3 Lai MC, Lombardo MV, Baron-Cohen S. Autism. Lancet 383(9920), 896-910 (2014).

4 Gadke DL, Mckinney C, Oliveros A. Autism spectrum disorder symptoms and comorbidity in emerging adults. Child. Psychiatry Hum. Dev. doi: 10.1007/s10578-015-05569 (2015) (Epub ahead of print).

5 Zafeiriou DI, Ververi A, Dafoulis V, Kalyva E, Vargiami E. Autism spectrum disorders: the quest for genetic syndromes. Am. J. Med. Genet. B 162B(4), 327-366 (2013).

6 Croen LA, Zerbo O, Qian Y et al. The health status of adults on the autism spectrum. Autism 19(7), 814-823 (2015).
7 Matson JL, Shoemaker M. Intellectual disability and its relationship to autism spectrum disorders. Res. Dev. Disabil. 30(6), 1107-1114 (2009).

8 Betancur C. Etiological heterogeneity in autism spectrum disorders: more than 100 genetic and genomic disorders and still counting. Brain Res. 1380, 42-77 (2011).

9 Bourgeron T. From the genetic architecture to synaptic plasticity in autism spectrum disorder. Nat. Rev. Neurosci. 16(9), 551-563 (2015).

10 Marshall CR, Noor A, Vincent JB et al. Structural variation of chromosomes in autism spectrum disorder. Am. J. Hum. Genet. 82(2), 477-488 (2008).

11 Lambert N, Wermenbol V, Pichon B et al. A familial heterozygous null mutation of MET in autism spectrum disorder. Autism Res. 7(5), 617-622 (2014).

12 De Rubeis S, He X, Goldberg AP et al. Synaptic, transcriptional and chromatin genes disrupted in autism. Nature 515(7526), 209-215 (2014).

13 Iossifov I, O'Roak BJ, Sanders SJ et al. The contribution of de novo coding mutations to autism spectrum disorder. Nature 515(7526), 216-221 (2014). 
14 Woodbury-Smith M, Paterson AD, Thiruvahindrapduram B et al. Using extended pedigrees to identify novel autism spectrum disorder (ASD) candidate genes. Hum. Genet. 134(2), 191-201 (2015).

15 Krumm N, O'roak BJ, Shendure J, Eichler EE. A de novo convergence of autism genetics and molecular neuroscience. Trends Neurosci. 37(2), 95-105 (2014).

16 Sandin S, Lichtenstein P, Kuja-Halkola R, Larsson H, Hultman CM, Reichenberg A. The familial risk of autism. JAMA 311 1770-1777 (2014).

17 Chaste P, Klei L, Sanders SJ et al. A genome-wide association study of autism using the Simons Simplex Collection: does reducing phenotypic heterogeneity in autism increase genetic homogeneity? Biol. Psychiatry 77(9), 775-784 (2014).

18 Williams EL, Casanova MF. Above genetics: lessons from cerebral development in autism. Transl. Neurosci. 2(2), 106-120 (2011).

19 Casanova MF. Autism as a sequence: from heterochronic germinal cell divisions to abnormalities of cell migration and cortical dysplasias. Med. Hypotheses 83(1), 32-38 (2014).

- Presents a conceptual framework for classifying idiopathic autism incorporating neuropathological mechanisms acting during development.

20 Gupta S, Ellis SE, Ashar FN et al. Transcriptome analysis reveals dysregulation of innate immune response genes and neuronal activity-dependent genes in autism. Nat. Commun. 5, 5748 (2014).

21 Zhang B, Horvath S. A general framework for weighted gene co-expression network analysis. Stat. Appl. Genet. Mol. Biol. 4, 17 (2005).

22 Winden KD, Oldham MC, Mirnics K et al. The organization of the transcriptional network in specific neuronal classes. Mol. Systems Biol. 5, 291 (2009).

23 Oldham MC, Konopka G, Iwamoto K et al. Functional organization of the transcriptome in human brain. Nat. Neurosci. 11(11), 1271-1282 (2008).

24 Konopka G, Friedrich T, Davis-Turak J et al. Humanspecific transcriptional networks in the brain. Neuron 75 , 601-617 (2012).

25 Voineagu I, Wang X, Johnston P et al. Transcriptomic analysis of autistic brain reveals convergent molecular pathology. Nature 474(7351), 380-384 (2011).

- First large-scale transcriptome study of autism brain.

26 Voineagu I, Eapen V. Converging pathways in autism spectrum disorders: interplay between synaptic and immune responses. Front. Hum. Neurosci. 7, 738 (2013).

27 Paolicelli RC, Bolasco G, Pagani F et al. Synaptic pruning by microglia is necessary for normal brain development. Science 333(6048), 1456-1458 (2011).

28 Schafer DP, Stevens B. Phagocytic glial cells: sculpting synaptic circuits in the developing nervous system. Curr. Opin. Neurobiol. 23(6), 1034-1040 (2013).

29 Piochon C, Kloth AD, Grasselli G et al. Cerebellar plasticity and motor learning deficits in a copy-number variation mouse model of autism. Nat. Commun. 5, 5586 (2014).
30 Levenson JM, Roth TL, Lubin FD et al. Evidence that DNA (cytosine-5) methyltransferase regulates synaptic plasticity in the hippocampus. J. Biol. Chem. 281(23), 15763-15773 (2006).

31 Zovkic IB, Guzman-Karlsson MC, Sweatt JD. Epigenetic regulation of memory formation and maintenance. Learn. Mem. 20(2), 61-74 (2013).

32 Oliveira AM, Hemstedt TJ, Bading H. Rescue of agingassociated decline in Dnmt3a2 expression restores cognitive abilities. Nat. Neurosci. 15(8), 1111-1113 (2012).

33 Grayson DR, Guidotti A. The dynamics of DNA methylation in schizophrenia and related psychiatric disorders. Neuropsychopharmacology 38(1), 138-166 (2013).

34 Millan MJ. An epigenetic framework for neurodevelopmental disorders: from pathogenesis to potential therapy. Neuropharmacology 68, 2-82 (2013).

35 Robertson KD, Jones PA. DNA methylation: past, present and future directions. Carcinogenesis 21(3), 461-467 (2000).

36 Irizarry RA, Ladd-Acosta C, Wen B et al. The human colon cancer methylome shows similar hypo- and hypermethylation at conserved tissue-specific CpG island shores. Nat. Genet. 41, 178-186 (2009).

37 Xie W, Barr CL, Kim A et al. Base-resolution analyses of sequence and parent-of-origin dependent DNA methylation in the mouse genome. Cell 148(4), 816-831 (2012).

38 Varley KE, Gertz J, Bowling KM et al. Dynamic DNA methylation across diverse human cell lines and tissues. Genome Res. 23(3), 555-567 (2013).

39 Guo JU, Su Y, Shin JH et al. Distribution, recognition and regulation of non-CpG methylation in the adult mammalian brain. Nat. Neurosci. 17(2), 215-222 (2014).

40 Lister R, Mukamel EA, Nery JR et al. Global epigenomic reconfiguration during mammalian brain development. Science 341(6146), 1237905 (2013).

- Provided genome-wide dynamics of DNA methylation at single-base resolution in human and mouse frontal cortex from early life through adulthood. Established that non- $\mathrm{CpG}$ methylation is an abundant methyl mark in the genome.

41 Jin B, Ernst J, Tiedemann RL et al. Linking DNA methyltransferases to epigenetic marks and nucleosome structure genome-wide in human tumor cells. Cell Rep. 2(5), 1411-1424 (2012).

42 Long HK, Blackledge NP, Klose RJ. ZF-CxxC domaincontaining proteins, $\mathrm{CpG}$ islands and the chromatin connection. Biochem. Soc. Trans. 41(3), 727-740 (2013).

43 Davies MN, Volta M, Pidsley R et al. Functional annotation of the human brain methylome identifies tissue-specific epigenetic variation across brain and blood. Genome Biol. 13, R43 (2012)

44 Mill J, Tang T, Kaminsky Z et al. Epigenomic profiling reveals DNA-methylation changes associated with major psychosis. Am. J. Hum. Genet. 82(3), 696-711 (2008).

45 Illingworth RS, Gruenewald-Schneider U, De Sousa D et al. Inter-individual variability contrasts with regional homogeneity in the human brain DNA methylome. Nucleic Acids Res. 43(2), 732-744 (2015). 
46 Amir RE, Van Den Veyver IB, Wan M, Tran CQ, Francke $\mathrm{U}$, Zoghbi HY. Rett syndrome is caused by mutations in $\mathrm{X}$-linked MECP2, encoding methyl-CpG-binding protein 2. Nat. Genet. 23, 185-188 (1999).

47 Lewis JD, Meehan RR, Henzel WJ et al. Purification, sequence, and cellular localization of a novel chromosomal protein that binds to methylated DNA. Cell 69 (6), 905-914 (1992).

48 Meehan RR, Lewis JD, Bird AP. Characterization of $\mathrm{MeCP} 2$, a vertebrate DNA binding protein with affinity for methylated DNA. Nucleic Acids Res. 20 (19), 5085-5092 (1992).

49 Nan X, Meehan RR, Bird A. Dissection of the methyl-CpG binding domain from the chromosomal protein MeCP2. Nucleic Acids Res. 21(21), 4886-4892 (1993).

50 Nan X, Ng HH, Johnson CA et al. Transcriptional repression by the methyl-CpG-binding protein $\mathrm{MeCP} 2$ involves a histone deacetylase complex. Nature 393(6683), 386-389 (1998).

51 Hendrich B, Bird A. Identification and characterization of a family of mammalian methyl-CpG binding proteins. Mol. Cell Biol. 18(11), 6538-6547 (1998).

52 Bird AP, Wolffe AP. Methylation-induced repression - belts, braces, and chromatin. Cell 99(5), 451-454 (1999).

53 Gruenbaum Y, Naveh-Many T, Cedar H, Razin A. Sequence specificity of methylation in higher plant DNA. Nature 292(5826), 860-862 (1981).

54 Doerfler W. DNA methylation and gene activity. Annu. Rev. Biochem. 52, 93-124 (1983).

55 Bachman M, Uribe-Lewis S, Yang X, Williams M, Murrell A, Balasubramanian S. 5-Hydroxymethylcytosine is a predominantly stable DNA modification. Nat. Chem. 6(12), 1049-1055 (2014).

56 Gabel HW, Kinde B, Stroud H et al. Disruption of DNA-methylation-dependent long gene repression in Rett syndrome. Nature 522(7554), 89-93 (2015).

57 Mellen M, Ayata P, Dewell S, Kriaucionis S, Heintz N. $\mathrm{MeCP} 2$ binds to $5 \mathrm{hmC}$ enriched within active genes and accessible chromatin in the nervous system. Cell 151(7), 1417-1430 (2012).

58 Lasalle JM, Yasui DH. Evolving role of MeCP2 in Rett syndrome and autism. Epigenomics 1(1), 119-130 (2009).

59 Pickett J, London E. The neuropathology of autism: a review. J. Neuropathol. Exp. Neurol. 64(11), 925-935 (2005).

60 Armstrong DD. Neuropathology of Rett syndrome. J. Child Neurol. 20(9), 747-753 (2005).

61 Phillips M, Pozzo-Miller L. Dendritic spine dysgenesis in autism related disorders. Neurosci. Lett. 601, 30-40 (2015).

62 Yasui DH, Xu H, Dunaway KW, Lasalle JM, Jin LW, Maezawa I. MeCP2 modulates gene expression pathways in astrocytes. Mol. Autism 4(1), 3 (2013).

63 Olson CO, Zachariah RM, Ezeonwuka CD, Liyanage VR, Rastegar M. Brain region-specific expression of MeCP2 isoforms correlates with DNA methylation within Mecp2 regulatory elements. PLoS ONE 9(3), e90645 (2014).
64 Skene PJ, Illingworth RS, Webb S et al. Neuronal MeCP2 is expressed at near histone-octamer levels and globally alters the chromatin state. Mol. Cell 37(4), 457-468 (2010).

65 Chen WG, Chang Q, Lin Y et al. Derepression of BDNF transcription involves calcium-dependent phosphorylation of MeCP2. Science 302(5646), 885-889 (2003).

66 Martinowich K, Hattori D, Wu H et al. DNA methylationrelated chromatin remodeling in activity-dependent BDNF gene regulation. Science 302 (5646), 890-893 (2003).

67 Gonzales ML, Adams S, Dunaway KW, Lasalle JM. Phosphorylation of distinct sites in MeCP2 modifies cofactor associations and the dynamics of transcriptional regulation. Mol. Cell. Biol. 32(14), 2894-2903 (2012).

68 Cohen S, Gabel HW, Hemberg M et al. Genome-wide activity-dependent $\mathrm{MeCP} 2$ phosphorylation regulates nervous system development and function. Neuron 72(1), 72-85 (2011).

69 Bellini E, Pavesi G, Barbiero I et al. MeCP2 posttranslational modifications: a mechanism to control its involvement in synaptic plasticity and homeostasis? Front. Cell. Neurosci. 8, 236 (2014).

70 Chao HT, Chen H, Samaco RC et al. Dysfunction in GABA signalling mediates autism-like stereotypies and Rett syndrome phenotypes. Nature 468(7321), 263-269 (2010).

71 Della Ragione F, Filosa S, Scalabri F, D'Esposito M. MeCP2 as a genome-wide modulator: the renewal of an old story. Front. Genet. 3, 181 (2012).

72 Kundakovic M, Chen Y, Guidotti A, Grayson DR. The reelin and GAD67 promoters are activated by epigenetic drugs that facilitate the disruption of local repressor complexes. Mol. Pharmacol. 75(2), 342-354 (2009).

73 Chahrour M, Jung SY, Shaw C et al. MeCP2, a key contributor to neurological disease, activates and represses transcription. Science 320(5880), 1224-1229 (2008).

74 Zhubi A, Cook EH, Guidotti A, Grayson DR. Epigenetic mechanisms in autism spectrum disorder. Int. Rev. Neurobiol. 115, 203-244 (2014).

75 Kriaucionis S, Heintz N. The nuclear DNA base 5-hydroxymethylcytosine is present in Purkinje neurons and the brain. Science 324(5929), 929-930 (2009).

- Establishes the presence of 5-hydroxymethylcytosine as an abundant DNA modification in Purkinje neurons of the cerebellum.

76 Tahiliani M, Koh KP, Shen Y et al. Conversion of 5-methylcytosine to 5-hydroxymethylcytosine in mammalian DNA by MLL partner TET1. Science 324(5929), 930-935 (2009).

77 Sun W, Zang L, Shu Q, Li X. From development to diseases: the role of $5 \mathrm{hmC}$ in brain. Genomics 104(5), 347-351 (2014).

78 Yu M, Hon GC, Szulwach KE et al. Base-resolution analysis of 5-hydroxymethylcytosine in the mammalian genome. Cell 149(6), 1368-1380 (2012).

79 Szulwach KE, Jin P. Integrating DNA methylation dynamics into a framework for understanding epigenetic codes. Bioessays 36(1), 107-117 (2014). 
80 Lu F, Liu Y, Jiang L, Yamaguchi S, Zhang Y. Role of Tet proteins in enhancer activity and telomere elongation. Genes Dev. 28(19), 2103-2119 (2014).

81 Wen L, Tang F. Genomic distribution and possible functions of DNA hydroxymethylation in the brain. Genomics 104(5), 341-346 (2014).

82 Wen L, Li X, Yan L et al. Whole-genome analysis of 5-hydroxymethylcytosine and 5-methylcytosine at base resolution in the human brain. Genome Biol. 15(3), R49 (2014).

- Used TET-assisted bisulfite sequencing to obtain the distribution and amounts 5-methylcytosine and 5-hydroxymethylcytosine at base resolution in human brain.

83 Lu X, Han D, Zhao BS et al. Base-resolution maps of 5-formylcytosine and 5-carboxylcytosine reveal genome-wide DNA demethylation dynamics. Cell Res. 25(3), 386-389 (2015).

84 Ito S, Shen L, Dai Q et al. Tet proteins can convert 5-methylcytosine to 5-formylcytosine and 5-carboxylcytosine. Science 333(6047), 1300-1303 (2011).

85 Cadet J, Wagner JR. TET enzymatic oxidation of 5-methylcytosine, 5-hydroxymethylcytosine and 5-formylcytosine. Mutat. Res. Genet. Toxicol. Environ. Mutagen. 764-765 18-35 (2014).

86 Spruijt CG, Gnerlich F, Smits AH et al. Dynamic readers for 5-(hydroxy) methylcytosine and its oxidized derivatives. Cell 152(5), 1146-1159 (2013).

87 Iurlaro M, Ficz G, Oxley D et al. A screen for hydroxymethylcytosine and formylcytosine binding proteins suggests functions in transcription and chromatin regulation. Genome Biol. 14(10), R119 (2013).

88 Hashimoto H, Hong S, Bhagwat AS, Zhang X, Cheng X. Excision of 5-hydroxymethyluracil and 5-carboxylcytosine by the thymine DNA glycosylase domain: its structural basis and implications for active DNA demethylation. Nucleic Acids Res. 40 (20), 10203-10214 (2012).

89 Shen L, Wu H, Diep D et al. Genome-wide analysis reveals TET- and TDG-dependent 5-methylcytosine oxidation dynamics. Cell 153(3), 692-706 (2013).

90 Kohli RM, Zhang Y. TET enzymes, TDG and the dynamics of DNA demethylation. Nature 502(7472), 472-479 (2013).

91 Guo JU, Su Y, Zhong C, Ming GL, Song H. Hydroxylation of 5-methylcytosine by TET1 promotes active DNA demethylation in the adult brain. Cell 145(3), 423-434 (2011).

92 Yu H, Su Y, Shin J, Zhong C, Guo JU. Tet3 regulates synaptic transmission and homeostatic plasticity via DNA oxidation and repair. Nat. Neurosci.18(6), 836-843 (2015).

93 Nguyen A, Rauch TA, Pfeifer GP, Hu VW. Global methylation profiling of lymphoblastoid cell lines reveals epigenetic contributions to autism s pectrum disorders and a novel autism candidate gene, RORA, whose protein product is reduced in autistic brain. FASEB J. 24(8), 3036-3051 (2010).

94 James SJ, Shpyleva S, Melnyk S, Pavliv O, Pogribny IP. Complex epigenetic regulation of engrailed-2 (EN-2) homeobox gene in the autism cerebellum. Transl. Psychiatry 3, e232 (2013).

95 Nagarajan RP, Hogart AR, Gwye Y, Martin MR, Lasalle $\mathrm{JM}$. Reduced MeCP2 expression is frequent in autism frontal cortex and correlates with aberrant MECP2 promoter methylation. Epigenetics 1(4), e1-e11 (2006).

96 Nagarajan RP, Patzel KA, Martin M et al. MECP2 promoter methylation and $\mathrm{X}$ chromosome inactivation in autism. Autism Res. 1(3), 169-178 (2008).

97 Gregory SG, Connelly JJ, Towers AJ et al. Genomic and epigenetic evidence for oxytocin receptor deficiency in autism. BMC Med. 7, 62 (2009).

98 Zhu L, Wang X, Li XL et al. Epigenetic dysregulation of SHANK3 in brain tissues from individuals with autism spectrum disorders. Hum. Mol. Genet. 23(6), 1563-1578 (2014).

99 Scoles HA, Urraca N, Chadwick SW, Reiter LT, Lasalle JM. Increased copy number for methylated maternal 15q duplications leads to changes in gene and protein expression in human cortical samples. Mol. Autism 2(1), 19 (2011).

100 Ginsberg MR, Rubin RA, Falcone T, Ting AH, Natowicz MR. Brain transcriptional and epigenetic associations with autism. PLoS ONE 7(9), e44736 (2012).

101 Ladd-Acosta C, Hansen KD, Briem E, Fallin MD, Kaufmann WE, Feinberg AP. Common DNA methylation alterations in multiple brain regions in autism. Mol. Psychiatry 19(8), 862-871 (2013).

102 Fukuoka Y, Inaoka H, Noshiro M. Adaptive threshold for detecting differentially expressed genes in microarray data - a simulation study to investigate its performance. Conf. Proc. IEEE Eng. Med. Biol. Soc. 2010, 5516-5519 (2010).

103 Gartlan KH, Belz GT, Tarrant JM et al. A complementary role for the tetraspanins CD37 and Tssc6 in cellular immunity. J. Immunol. 185(6), 3158-3166 (2010).

104 Goschnick MW, Jackson DE. Tetraspanins-structural and signalling scaffolds that regulate platelet function. Mini Rev. Med. Chem. 7(12), 1248-1254 (2007).

105 Li X, Ito M, Zhou F et al. A maternal-zygotic effect gene, Zfp57, maintains both maternal and paternal imprints. Dev. Cell 15(4), 547-557 (2008).

106 Strogantsev R, Ferguson-Smith AC. Proteins involved in establishment and maintenance of imprinted methylation marks. Brief Funct. Genomics 11(3), 227-239 (2012).

107 Zuo X, Sheng J, Lau HT et al. Zinc finger protein ZFP57 requires its co-factor to recruit DNA methyltransferases and maintains DNA methylation imprint in embryonic stem cells via its transcriptional repression domain. J. Biol. Chem. 287(3), 2107-2118 (2012).

108 Wong CC, Meaburn EL, Ronald A et al. Methylomic analysis of monozygotic twins discordant for autism spectrum disorder and related behavioural traits. Mol. Psychiatry 19(4), 495-503 (2014).

109 Nardone S, Sams DS, Reuveni E et al. DNA methylation analysis of the autistic brain reveals multiple dysregulated biological pathways. Transl. Psychiatry 4, e433 (2014).

- Genome-wide DNA methylation data are provided that show hypermethylation and downregulation of genes 
associated with synaptic function and hypomethylation and upregulation of genes involved in immune function.

110 Feng J, Zhou Y, Campbell SL et al. Dnmt1 and Dnmt3a maintain DNA methylation and regulate synaptic function in adult forebrain neurons. Nat. Neurosci. 13(4), 423-430 (2010).

111 Atladottir HO, Thorsen P, Ostergaard L et al. Maternal infection requiring hospitalization during pregnancy and autism spectrum disorders. J. Autism Disord. 40(12), 1423-1430), (2010)

112 Atladottir HO, Thorsen P, Schendel DE, Ostergaard L, Lemcke S, Parner ET. Association of hospitalization for infection in childhood with diagnosis of autism spectrum disorders: a Danish cohort study. Arch. Pediatr. Adolesc. Med. 164 470-477 (2010)

113 Lee BK, Magnusson C, Gardner RM et al. Maternal hospitalization with infection during pregnancy and risk of autism spectrum disorders. Brain Behav. Immun. 44, 100-105 (2015).

114 Lan X, Adams C, Landers M et al. High resolution detection and analysis of $\mathrm{CpG}$ dinucleotides methylation using MBD-Seq technology. PLoS ONE 6(7), e22226 (2011).

115 Guintivano J, Aryee MJ, Kaminsky ZA. A cell epigenotype specific model for the correction of brain cellular heterogeneity bias and its application to age, brain region and major depression. Epigenetics 8(3), 290-302 (2013).

116 Wang T, Pan Q, Lin L et al. Genome-wide DNA hydroxymethylation changes are associated with neurodevelopmental genes in the developing human cerebellum. Hum Mol. Genet. 21, 5500-5510 (2012).

117 Zhubi A, Chen Y, Dong E, Cook EH, Guidotti A, Grayson DR. Increased binding of MeCP2 to the GAD1 and RELN promoters may be mediated by an enrichment of $5-\mathrm{hmC}$ in autism spectrum disorder (ASD) cerebellum. Transl. Psychiatry 4, e349 (2014).

118 James SJ, Shpyleva S, Melnyk S, Pavliv O, Pogribne IP. Elevated 5-hydroxymethylcytosine in the Engrailed-2 (EN2) promoter is associated with increased gene expression and decreased MeCP2 binding in autism cerebellum. Transl. Psychiatry 4, e460 (2014).

119 Zhubi A, Chen Y, Dong E, Cook EH, Guidotti A, Grayson DR. Increased binding of MeCP2 and DNMT1 to RELN and GAD1 regulatory regions is associated with downregulation of mRNA expression of RELN and GAD1 in the postmoretem prefrontal cortex of autism spectrum disorder (ASD) brain samples. Program No. XXX.XX Neuroscience Meeting Planner. Presented at: Society for Neuroscience. Chicago, IL, USA, 17-21 October 2015.

120 Kimura H, Shiota K. Methyl-CpG binding protein, $\mathrm{MeCP} 2$, is a target molecule for maintenance DNA methyltransferase, Dnmt1. J. Biol. Chem. 278, 4806-4812 (2003).

121 Blackledge NP, Thomson JP, Skene PJ. CpG island chromatin is shaped by recruitment of ZF-CxxC proteins. Cold Spring Harb. Perspect. Biol. 5, a018648 (2010a).

122 Georgel PT, Horowitz-Scherer RA, Adkins N, Woodcock CL, Wade PA, Hansen JC. Chromatin compaction by human MeCP2: assembly of novel secondary chromatin structures in the absence of DNA methylation. J. Biol. Chem. 278, 32181-32188 (2003).

123 Lyall K, Schmidt RJ, Hertz-Picciotto I. Maternal lifestyle and environmental risk factors for autism spectrum disorders. Int. J. Epidemiol. 43(2), 443-464 (2014).

124 Schaevitz LR, Berger-Sweeney JE. Gene-environment interactions and epigenetic pathways in autism: the importance of one-carbon metabolism. ILAR J. 53(3-4), 322-340 (2012)

125 Kofink D, Boks MP, Timmers HT, Kas MJ. Epigenetic dynamics in psychiatric disorders: environmental programming of neurodevelopmental processes. Neurosci. Biobehav. Rev. 37(5), 831-845 (2013).

126 Lasalle JM. A genomic point-of-view on environmental factors influencing the human brain methylome. Epigenetics 6(7), 862-869 (2011).

- Establishes a theoretical framework for thinking about how early environmental influences impact the DNA methylome and the relevance of one carbon metabolism to autism.

127 Kiser DP, Rivero O, Lesch KP. Annual research review: the (epi)genetics of neurodevelopmental disorders in the era of whole-genome sequencing--unveiling the dark matter. J. Child Psychol. Psychiatry 56(3), 278-295 (2015).

128 Koufaris C, Sismani C. Modulation of the genome and epigenome of individuals susceptible to autism by environmental risk factors. Int. J. Mol. Sci. 16(4), 8699-8718 (2015)

129 Ronald A, Pennell CE, Whitehouse AJ. Prenatal maternal stress associated with ADHD and autistic traits in early childhood. Front. Psychol. 1, 223 (2010).

130 Fine R, Zhang J, Stevens HE. Prenatal stress and inhibitory neuron systems: implications for neuropsychiatric disorders. Mol. Psychiatry 19(6), 641-651 (2014).

131 Stevens HE, Su T, Yanagawa Y, Vaccarino FM. Prenatal stress delays inhibitory neuro progenitor migration in the developing neucortex. Psychoneuroendocrinology 38, 509-521 (2013)

132 Dong E, Dzitoyeva SG, Matrisciano F, Tueting P, Grayson DR, Guidotti A. Brain-derived neurotrophic factor epigenetic modifications associated with schizophrenialike phenotype induced by prenatal stress in mice. Biol. Psychiatry 77(6), 589-596 (2015).

133 Matrisciano F, Tueting P, Dalal I et al. Epigenetic modifications of GABAergic interneurons are associated with the schizophrenia-like phenotype induced by prenatal stress in mice. Neuropharmacology 68, 184-194 (2013).

134 Bissonette GB, Bae MH, Suresh T, Jaffe DE, Powell EM. Prefrontal cognitive deficits in mice with altered cerebral cortical GABAergic interneurons. Behav. Brain Res. 259, 143-151 (2014).

135 Zikopoulos B, Barbas H. Altered neural connectivity in excitatory and inhibitory cortical circuits in autism. Front. Hum. Neurosci. 7, 609 (2013).

136 Wohr M, Orduz D, Gregory P et al. Lack of parvalbumin in mice leads to behavioral deficits relevant to all human 
autism core symptoms and related neural morphofunctional abnormalities. Transl. Psychiatry 5, e525 (2015).

137 Fukumoto K, Morita T, Mayanagi T et al. Detrimental effects of glucocorticoids on neuronal migration during brain development. Mol. Psychiatry 14(12), 1119-1131 (2009).

138 Mead J, Ashwood P. Evidence supporting an altered immune response in ASD. Immunol. Lett. 163(1), 49-55 (2015).

139 Goines PE, Ashwood P. Cytokine dysregulation in autism spectrum disorders (ASD): possible role of the environment. Neurotoxicol. Teratol. 36, 67-81 (2013).

140 Knuesel I, Chicha L, Britschgi M et al. Maternal immune activation and abnormal brain development across CNS disorders. Nat. Rev. Neurol. 10(11), 643-660 (2014).

141 Zerbo O, Iosif AM, Walker C, Ozonoff S, Hansen RL, Hertz-Picciotto I. Is maternal influenza or fever during pregnancy associated with autism or developmental delays? Results from the CHARGE (CHildhood Autism Risks from Genetics and Environment) study. J. Autism Dev. Disord. 43(1), 25-33 (2013).

142 Zerbo O, Qian Y, Yoshida C, Grether JK, Van De Water J, Croen LA. Maternal infection during pregnancy and autism spectrum disorders. J. Autism Dev. Disord. doi:10.1007/ s10803-013-2016-3 (2013) (Epub ahead of print).

143 Rose D, Ashwood P. Potential cytokine biomarkers in autism spectrum disorders. Biomark. Med. 8(9), 1171-1181 (2014).

144 Lyall K, Ashwood P, Van De Water J, Hertz-Picciotto I. Maternal immune-mediated conditions, autism spectrum disorders, and developmental delay. J. Autism Dev. Disord. 44(7), 1546-1555 (2014).

145 Mcdougle CJ, Landino SM, Vahabzadeh A et al. Toward an immune-mediated subtype of autism spectrum disorder. Brain Res. 1617, 72-92 (2014).

146 Pramparo T, Pierce K, Lombardo MV et al. Prediction of autism by translation and immune/inflammation coexpressed genes in toddlers from pediatric community practices. JAMA Psychiatry 72(4), 386-394 (2015).

147 McCarthy SE, Gillis J, Kramer M et al. De novo mutations in schizophrenia implicate chromatin remodeling and support a genetic overlap with autism and intellectual disability. Mol. Psychiatry 19, 652-658 (2014).

148 Horvath S, Mirnics K. Immune system disturbances in schizophrenia. Biol. Psychiatry 75, 316-322 (2014).

149 Brown AS. Epidemiologic studies of exposure to prenatal infection and risk of schizophrenia and autism. Dev. Neurobiol. 72(10), 1272-1276 (2012).

150 Jimenez-Chillaron JC, Diaz R, Martinez D et al. The role of nutrition on epigenetic modifications and their implications on health. Biochimie 94(11), 2242-2263 (2012).

151 Zeisel SH. The supply of choline is important for fetal progenitor cells. Semin. Cell Dev. Biol. 22(6), 624-628 (2011).

152 O'Dushlaine C, Rossin L, Lee PH et al. Psychiatric genomewide association study analyses implicate neuronal, immune and histone pathways. Nat. Neurosci. 18(2), 199-209 (2015).

153 Schmidt RJ, Hansen RL, Hartiala J et al. Prenatal vitamins, one-carbon metabolism gene variants, and risk for autism. Epidemiology 22(4), 476-485 (2011).
154 Schmidt RJ, Tancredi DJ, Ozonoff S et al. Maternal periconceptional folic acid intake and risk of autism spectrum disorders and developmental delay in the CHARGE (CHildhood Autism Risks from Genetics and Environment) case-control study. Am. J. Clin. Nutr. 96(1), 80-89 (2012).

155 Suren P, Roth C, Bresnahan M et al. Association between maternal use of folic acid supplements and risk of autism spectrum disorders in children. JAMA 309 (6), 570-577 (2013).

156 Baccarelli A, Bollati V. Epigenetics and environmental chemicals. Curr. Opin. Pediatr. 21(2), 243-251 (2009).

157 Lee DH, Jacobs DR Jr, Porta M. Hypothesis: a unifying mechanism for nutrition and chemicals as lifelong modulators of DNA hypomethylation. Environ. Health. Perspect. 117(12), 1799-1802 (2009).

158 Lyall K, Munger KL, O’Reilly EJ, Santangelo SL, Ascherio A. Maternal dietary fat intake in association with autism spectrum disorders. Am. J. Epidemiol. 178(2), 209-220 (2013).

159 Patrick RP, Ames BN. Vitamin D hormone regulates serotonin synthesis. Part 1: relevance for autism. FASEB J. 28(6), 2398-2413 (2014).

160 Zafeiriou DI, Ververi A, Vargiami E. The serotonergic system: its role in pathogenesis and early developmental treatment of autism. Curr. Neuropharmacol. 7(2), 150-157 (2009).

161 Whitehouse AJ, Holt BJ, Serralha M, Holt PG, Kusel MM, Hart PH. Maternal serum vitamin D levels during pregnancy and offspring neurocognitive development. Pediatrics 129(3), 485-493 (2012).

162 Fetahu IS, Hobaus J, Kallay E. Vitamin D and the epigenome. Front. Physiol. 5, 164 (2014).

163 Volk HE, Lurmann F, Penfold B, Hertz-Picciotto I, Mcconnell R. Traffic-related air pollution, particulate matter, and autism. JAMA Psychiatry 70 (1), 71-77 (2013).

164 Rossignol DA, Genuis SJ, Frye RE. Environmental toxicants and autism spectrum disorders: a systematic review. Transl. Psychiatry 4, e360 (2014).

165 Larsson M, Weiss B, Janson S, Sundell J, Bornehag CG. Associations between indoor environmental factors and parental-reported autistic spectrum disorders in children 6-8 years of age. Neurotoxicology 30(5), 822-831 (2009).

166 Stein TP, Schluter MD, Steer RA, Guo L, Ming X. Bisphenol a exposure in children with autism spectrum disorders. Autism Res. 8(3), 272-283 (2015).

167 Froehlich-Santino W, Londono Tobon A, Cleveland S et al. Prenatal and perinatal risk factors in a twin study of autism spectrum disorders. J. Psychiatr. Res. 54, 100-108 (2014).

168 Schaafsma SM, Pfaff DW. Etiologies underlying sex differences in Autism Spectrum Disorders. Front. Neuroendocrinol. 35(3), 255-271 (2014).

169 Shelton JF, Geraghty EM, Tancredi DJ et al. Neurodevelopmental disorders and prenatal residential proximity to agricultural pesticides: the CHARGE study. Environ. Health Perspect. 122(10), 1103-1109 (2014).

170 Christensen J, Gronborg TK, Sorensen MJ et al. Prenatal valproate exposure and risk of autism spectrum disorders and childhood autism. JAMA 309(16), 1696-1703 (2013). 
171 Alsaeed I, Al-Somali F, Sakhnini L et al. Autism-relevant social abnormalities in mice exposed perinatally to extremely low frequency electromagnetic fields. Int. J. Dev. Neurosci 37, 58-64 (2014).

172 Hutsler JJ, Casanova MF. Review: Cortical construction in autism spectrum disorder: columns, connectivity and the subplate. Neuropathol. Appl. Neurobiol. doi:10.1111/ nan.12227 (2015) (Epub ahead of print).

173 Casanova EL, Casanova MF. Genetics studies indicate that neural induction and early neuronal maturation are disturbed in autism. Front. Cell. Neurosci. 8, 397 (2014).

174 Barua S, Junaid MA. Lifestyle, pregnancy and epigenetic effects. Epigenomics 7(1), 85-102 (2015).

175 Mostafa GA, El-Sherif DF, Al-Ayadhi LY. Systemic autoantibodies in children with autism. J. Neuroimmunol. 272(1-2), 94-98 (2014)

176 Mefford HC, Batshaw ML, Hoffman EP. Genomics, intellectual disability, and autism. N. Engl. J. Med. 366(8), 733-743 (2012).

177 Polyak A, Kubina RM, Girirajan S. Comorbidity of intellectual disability confounds ascertainment of autism: implications for genetic diagnosis. Am. J. Med. Genet. Part B Neuropsychiatr. Genet. 168(7), 600-608 (2015).

178 Ch'ng C, Kwok W, Rogic S, Pavlidis P. Meta-analysis of gene expression in autism spectrum disorder. Autism Res. doi:10.1002/aur.1475 (2015) (Epub ahead of print).

179 Li J, Shi M, Ma Z et al. Integrated systems analysis reveals a molecular network underlying autism spectrum disorders. Mol. Syst. Biol. 10, 774 (2014).
180 Parikshak NN, Luo R, Zhang A et al. Integrative functional genomic analyses implicate specific molecular pathways and circuits in autism. Cell 155(5), 1008-1021 (2013).

181 Willsey AJ, Sanders SJ, Li M et al. Coexpression networks implicate human midfetal deep cortical projection neurons in the pathogenesis of autism. Cell 155(5), 997-1007 (2013).

- This group used coexpression network analysis of ASDassociated mutations and expression data to identify time periods, brain regions and cell types likely to underlie the pathophysiology of ASD. They identify midfetal layer 5/6 cortical projection neurons as an important convergence point based on this approach.

182 Liu L, Lei J, Sanders SJ et al. DAWN: a framework to identify autism genes and subnetworks using gene expression and genetics. Mol. Autism 5(1), 22 (2014).

183 Chang J, Gilman SR, Chiang AH, Sanders SJ, Vitkup D. Genotype to phenotype relationships in autism spectrum disorders. Nat. Neurosci. 18(2), 191-198 (2015).

184 Pinto D, Delaby E, Merico D et al. Convergence of genes and cellular pathways dysregulated in autism spectrum disorders. Am. J. Hum. Genet. 94(5), 677-694 (2014).

185 Blais A, Dynlacht BD. Constructing transcriptional regulatory networks. Genes Dev. 19(13), 1499-1511 (2005).

186 Darnell JC, Klann E. The translation of translational control by FMRP: therapeutic targets for FXS. Nat. Neurosci. 16(11), 1530-1536 (2013). 